\title{
A SINGLE-CONSIGNOR MULTI-CONSIGNEE MULTI-ITEM MODEL WITH PERMISSIBLE PAYMENT DELAY, DELAYED SHIPMENT AND VARIABLE LEAD TIME UNDER CONSIGNMENT STOCK POLICY
}

\author{
B. KARTHICK* * AND R. UthaYAKUMAR
}

\begin{abstract}
This article proposes a two-level fuzzy supply chain inventory model, in which a single consignor delivers multiple items to the multiple consignees with the consignment stock agreement. The lead time is incorporated into the model and is considered a variable for obtaining optimal replenishment decisions. In addition, crashing cost is employed to reduce the lead time duration. This article investigates four different cases under controllable lead time to analyze the best strategy, focusing on two delays such as delay-in-payments and delay-in-shipment. In all four cases, all associated inventory costs are treated as a trapezoidal fuzzy number, and a signed distance method is employed to defuzzify the fuzzy inventory cost. An efficient optimization technique is adopted to find the optimal solution for the supply chain. Four numerical experiments are conducted to illustrate the four cases. Any one of these experimental results will provide the best solution for the ideal performance of the business under controllable lead time in the consignment stock policy. Finally, the managerial insights, conclusion and future direction of this model are provided.
\end{abstract}

Mathematics Subject Classification. 90B05.

Received July 8, 2020. Accepted July 25, 2021.

\section{INTRODUCTION}

In the supply chain, the consignment stock plays a vital role to attain a higher profit. Consignment stock (CS) is a business agreement where the consignor agrees to deliver the goods/products to the consignee without getting paid for the products in advance - the consignor still owns the products. The consignee pays for those products only when it sold. Inventory management is a crucial part of the consignment partnership process. This partnership has attracted many researchers' attention, and, as a result, numerous inventory models have been studied under the CS contract. Moreover, under CS policy, the retailer/buyer is referred to as the consignee and the supplier/manufacturer as the consignor. In the industrial market, the number of new products increases day by day depending on the customers' needs. On its basis, to attract new customers, many researchers have incorporated permissible payment delay to their models, saying that such incorporation will also enable greater profitability under the integrated supply chain.

Keywords. Consignment stock, controllable lead time, delay in shipment, delay in payment, fuzzy cost.

Department of Mathematics, The Gandhigram Rural Institute (Deemed to be University), Gandhigram 624302, Tamil Nadu, India.

*Corresponding author: karthickbalasubramani96@gmail.com

(C) The authors. Published by EDP Sciences, ROADEF, SMAI 2021 
Many inventory issues consider infinite storage in the buyer's warehouse, but almost all businesses face warehouse space limitations. Many researchers have developed a multi-inventory model that considers the number of shipments equal or unequal. If the buyer's warehouse has low capacity, the shipment is considered unequal. Therefore, such a space limitation plays an important role. Lead time in inventory management is the time period between placing an order to replenish inventory and receiving the order. The manufacturing methods and the management of stocks can also influence the lead time. Concerning production, it may take longer to build all the elements of a finished product on-site than to complete some off-site items. Therefore, it is crucial to consider the lead time as a variable.

The fuzzy logic techniques effectively solve complex, ill-defined problems characterized by environmental uncertainty and ambiguity of information. It allows for handling uncertain and imprecise knowledge and provides a robust framework for reasoning. Therefore, it has been confirmed that fuzzy logic is compelling in overcoming such uncertainty, and it describes a phenomenon in which a mathematical model or input data is unknown. Due to the uncertainty of the information and the complexity of the decision-making process, it is difficult for decision-makers to express their preferences using the exact numbers. In such a case, it is easy for them to use linguistic labels, i.e., fuzzy or vague terms, to express their preferences. Thus, the solution to these sorts of challenges can be found by considering an uncertain parameter with fuzzy numbers (see, for instance, [19,20,22]). Generally, fuzzy numbers are used to treat uncertain parameters. It is essential to understand uncertainty, to manage inventory strategies in supply chain management. In inventory models, there are uncertainties not only in demand for goods but also in the calculation of inventory-related costs, and some random (stochastic) techniques have been used to deal with these issues under such supply chain management's inventory policies. In such problems, uncertainties are shaped by probability distributions based on the past analysis; however, past data are not always accurate or reliable. Furthermore, it is difficult to determine and implement uncertainty in integrated inventory models. Therefore, fuzzy set-based techniques may be the best way to treat these uncertainties for the practical application of inventory concepts in the supply chain (see, for instance, [29]). Fuzziness describes event ambiguity, and it measures the degree to which an event occurs, not whether it occurs. Randomness describes the uncertainty of event occurrence, that is, an event occurs or not. Therefore, whether an event occurs is "random" and to what degree it occurs is "fuzzy". Moreover, randomness is an objective form of indeterminacy whose distribution function of random variables is deduced by applying statistical methods. Fuzziness is a subjective form of indeterminacy that is distinguished by the degree of belongingness to a set.

By combining all of the features as mentioned above, in this study, we have considered four different cases under controllable lead-time (CLT) in an uncertain environment, namely (i) CS policy with no delay in payment (NDIP) - no delay in the shipment (NDIS) under CLT, (ii) CS policy with delay in payment (DIP) - no delay in the shipment (NDIS) under CLT, (iii) CS policy with no delay in payment (NDIP) - delay in the shipment (DIS) under CLT, (iv) CS policy with delay in payment (DIP) - delay in the shipment (DIS) under CLT.

\section{LiterATURE REVIEW}

The literature review section covers the following topics: consignment stock policy, delay in payment, delay in shipment, controllable lead time, and CS policy in a fuzzy sense. We are particularly interested in research work dealing with two concepts: the allowable payment delay with interest and the delayed delivery in an ambiguous environment, which will bridge the existing literature and the current work.

\subsection{Consignment Stock policy}

Braglia and Zavanella [5] were the first researchers who proposed the inventory model under the consignment stock policy between the single vendor and a single buyer. Huang and Chen [16] showed the industrial strategy model in the supply chain following the CS policy. Zavanella and Zanoni [40] addressed the production inventory model under CS policy between the single-vendor multi-buyer. Srinivas and Rao [35] investigated and optimized the CS contract-based supply chain model for single-vendor multi-buyer with the genetic algorithm. Giri et al. [14] developed a three-tier supply chain model based on CS policy. Sarkar et al. [28] analyzed CS policy with a 
royalty reduction under a distribution-free approach. Gharaei et al. [12] designed the Vendor Managed Inventory (VMI) with the CS policy model and sharing multiple items between the single-vendor multi-buyer under greenhouse gas emissions and penalty. Giri and Masanta [13] examined the CS policy model under the consideration of learning and forgetting strategy with an uncertain return. Bylka [6] formulated the CS contract model with the limited warehouse capacity on the buyer's side. Sardar and Sarkar [25] investigated the supply chain model with advanced technology to solve unreliability. Sardar et al. [31] considered a CS agreement based model with radio frequency identification and machine learning. Chakraborty et al. [7] proposed a closed-loop supply chain model with CS policy. Çömez-Dolgan et al. [8] developed an inventory model in two different scenarios with untimely delivery costs.

\subsection{Delay in payment}

Aggarwal and Jaggi [1] illustrated the inventory model for deteriorating items by implementing permissible delay in payments. Sarkar [24] examined an imperfect production model with delayed payments and stock-based demand. Zahran et al. [39] studied the CS case with delay-in-payments for single-vendor and single-buyer. Shabani et al. [32] developed an inventory model with a two-warehouse inventory, fuzzy demand rate under permissible delay in payment. Ebrahimi et al. [9] proposed a two-echelon supply chain model with a delay in payment contract under stochastic promotional effort dependent demand.

\subsection{Delay in shipment}

Hill [15] suggested an integrated production-inventory model with the optimal production and shipment policy for the single-vendor single-buyer problem. Valentini and Zavanella [36] developed a consignment stock model with $k$ th delayed shipment under the industrial case. Yi and Sarker [37] analyzed the replenishment policy model with delayed deliveries under controllable lead time. Yu and Hsu [38] considered an integrated inventory model for defective items with unequal-sized shipments. Ganesh Kumar and Uthayakumar [10] developed an inventory model by considering the delayed shipments under VMI policy.

\subsection{Controllable lead time}

Jha and Shanker [18] developed the production inventory model by considering the crashing cost for multibuyer. Jamshidi et al. [17] considered a flexible inventory model with controllable lead time. Sarkar et al. [26] examined the effects of quality improvement and price discounts in the context of controllable lead time. Shin et al. [34] developed an inventory model following a continuous review methodology with variable lead time. Sarkar et al. [27] developed a model between single-vendor multi-buyer with varying production rate and controllable lead time. Ganguly et al. [11] designed the supply chain model with the influence of controllable lead time. Ahmad and Benkherouf [2] investigated an inventory model with replenishment decisions under partial backorder. Sharma et al. [33] analyzed the supply chain model with deteriorating products under varying lead time. Sarkar et al. [30] illustrated the deteriorating products-inventory model with varying demand and lead time.

\subsection{CS policy under fuzzy environment}

Ouyang and Yao [22] examined the distribution free inventory model with fuzzy demand. Björk [4] proposed an Economic Order Quantity (EOQ) model by considering the lead time, inventory level, and demand as a triangular fuzzy number, and defuzzification is done by using the signed distance method. Kazemi et al. [21] developed an inventory model by considering the inventory cost as the trapezoidal fuzzy number. Ali and Nakade [3] have developed a framework for examining the disruption of the supply chain in uncertain situations. Rani et al. [23] illustrated a model with carbon emission depended demand under a fuzzy environment. Sarkar et al. [29] suggested the supply chain model by assuming the inventory associated cost as a triangular fuzzy number under the signed distance method. Karthick and Uthayakumar [19] investigated the imperfect production inventory model with triangular fuzzy demand under the signed distance method. Karthick and 
TABLE 1. A comparison of the present model with related existing models.

\begin{tabular}{|c|c|c|c|c|c|c|c|}
\hline Reference & $\begin{array}{l}\text { CS } \\
\text { policy }\end{array}$ & $\begin{array}{l}\text { Multi } \\
\text { item }\end{array}$ & $\begin{array}{l}\text { Multi } \\
\text { consignee }\end{array}$ & $\begin{array}{l}\text { Delay in } \\
\text { payment }\end{array}$ & $\begin{array}{l}\text { Delay in } \\
\text { shipment }\end{array}$ & $\begin{array}{l}\text { Controllable } \\
\text { lead time }\end{array}$ & $\begin{array}{l}\text { Fuzzy } \\
\text { environment }\end{array}$ \\
\hline $\begin{array}{l}\text { Braglia and } \\
\text { Zavanella [5] }\end{array}$ & $\sqrt{ }$ & & & & & & \\
\hline Bylka [6] & $\sqrt{ }$ & & & & & & \\
\hline $\begin{array}{l}\text { Gharaei et al. } \\
{[12]}\end{array}$ & $\sqrt{ }$ & $\sqrt{ }$ & $\sqrt{ }$ & & & & \\
\hline $\begin{array}{l}\text { Huang and } \\
\text { Chen [16] }\end{array}$ & $\sqrt{ }$ & & & & & & \\
\hline $\begin{array}{l}\text { Karthick and } \\
\text { Uthayakumar } \\
{[20]}\end{array}$ & $\sqrt{ }$ & $\sqrt{ }$ & & & & & $\sqrt{ }$ \\
\hline $\begin{array}{l}\text { Sarkar et al. } \\
{[30]}\end{array}$ & & & & & $\sqrt{ }$ & & \\
\hline $\begin{array}{l}\text { Sarkar et al. } \\
{[29]}\end{array}$ & & & & & & & $\sqrt{ }$ \\
\hline $\begin{array}{l}\text { Valentini and } \\
\text { Zavanella [36] }\end{array}$ & $\sqrt{ }$ & & & & & & \\
\hline $\begin{array}{l}\text { Yi and Sarker } \\
{[37]}\end{array}$ & $\sqrt{ }$ & & & & $\sqrt{ }$ & $\sqrt{ }$ & \\
\hline $\begin{array}{l}\text { Zavanella and } \\
\text { Zanoni }[40]\end{array}$ & $\sqrt{ }$ & & $\sqrt{ }$ & & & & \\
\hline $\begin{array}{l}\text { Zahran et al. } \\
\text { [39] }\end{array}$ & $\sqrt{ }$ & & & $\sqrt{ }$ & & & \\
\hline Present model & $\sqrt{ }$ & $\sqrt{ }$ & $\sqrt{ }$ & $\sqrt{ }$ & $\sqrt{ }$ & $\sqrt{ }$ & $\sqrt{ }$ \\
\hline
\end{tabular}

Uthayakumar [20] developed a VMI-consignment stock policy model with multiple items and trapezoidal fuzzy number under the graded mean integration method.

\subsection{The literature gap in previous research}

From the above discussion, we observed that the CS policy model plays an essential role in business management. Braglia and Zavanella [5], Valentini and Zavanella [36], and Huang and Chen [16] developed a CS policy model for industrial purpose. Zavanella and Zanoni [40] extend the work of $[5,16,36]$ by considering the single buyer to multiple buyers. Yi and Sarker [37] examined the inventory model with CS agreement with the incorporation of variable lead time. Also, Zahran et al. [39] have analyzed the CS policy model with permissible payment delay. However, Zahran et al. [39], Yi and Sarker [37], Braglia and Zavanella [5], Valentini and Zavanella [36] and Huang and Chen [16] do not consider their models with multiple buyers with multiple products. Nevertheless, Zahran et al. [39] does not discuss how their model operates with controllable lead time. In trading, lead time plays a significant role in avoiding shortages, so lead time reduction is considered necessary. Furthermore, there is no inventory model in the literature for dealing with CS policy between a single consignor and multiple consignees with multiple products in a fuzzy environment. Based on that, in addition, this study presents four special cases associated with two delays: delay in shipping and delay in payment.

Contributions of various study articles from the existing literature are given in Table 1 . The rest of the paper has been comprised as follows: In Section 3, notations and assumptions are given to develop the model. In Section 4, four different cases are developed under controllable lead time in the fuzzy environment. The defuzzification process for the fuzzified total profit function is developed in Section 5. In Section 6, the solution procedure has been derived to find optimal solutions. Moreover, in this paper, all basic inventory cost is treated 
as a trapezoidal fuzzy number, and the defuzzification process is done using the signed distance method. Four numerical examples are considered for each case to validate this model in Section 7. Numerical discussions and managerial insights are given in Sections 8 and 9, respectively. Finally, the conclusion is given in Section 10.

\section{Problem Definition, notations And ASsumptions}

\subsection{Problem definition}

The consignor produces a certain quantity of goods and transfers them equally to each consignee. Once the goods are withdrawn from the consigned inventory, the consignee pays the consignor an equal payment in an equal interval scheme (see, for instance, [39]). Also, if the consignee's warehouse reaches the maximum stock level, the shipments will be delayed. This aside, lead time plays a crucial role in the supply chain, so lead time crashing cost is incorporated to reduce lead-time length. This study analyzes the consequences of delayed deliveries and delayed payments in four different cases with uncertain supply chain costs. In the first and second cases, the shipment is considered without delay, whereas it is considered delayed in the third and fourth cases. Similarly, in the second and fourth cases, the payment (with interest charges) to the consignor is considered with delay and in the first and third cases without delay.

In this paper, we develop a mathematical model using the notations and assumptions listed below.

\subsection{Notations}

The following notations will be used to develop the model.

\section{Indices}

$i \quad$ The index of items and $1 \leq i \leq z$, where $z$ is the total number of items

$j \quad$ The index of consignee's and $1 \leq j \leq y$, where $y$ is the total number of consignee

$c \quad$ The index of cases and $c=1,2,3,4$

\section{Parameters}

$\begin{array}{ll}S_{v i} & \text { Setup cost for } i \text { th item }(\$ / \text { setup }) \\ p_{i} & \text { Production rate of } i \text { th item }(\text { units } / \text { year }) \\ c_{p r i} & \text { Production cost of } i \text { th item }(\$ / \text { unit }) \\ c_{p i} & \text { Purchasing cost of raw materials for } i \text { th item }(\$ / \text { unit }) \\ \gamma_{i} & \text { Number of units needed to produce } i \text { th item } \\ t_{i j} & \text { Time of invoice of } i \text { th item for } j \text { th consignee } \\ d_{i j} & \text { Demand rate of } i \text { th item from } j \text { th consignee }(\text { units } / \text { year }) \\ O_{r i j} & \text { Ordering cost of } i \text { th item for } j \text { th consignee }(\$ / \text { order }) \\ h_{m i j}^{f} & \text { Consignor's financial holding cost of } i \text { th item for } j \text { th consignee }(\$ / \text { unit } / \text { year }) \\ h_{m i j}^{p} & \text { Consignor's physical holding cost of } i \text { th item for } j \text { th consignee }(\$ / \text { unit } / \text { year }) \\ h_{m i j} & \text { Consignor's holding cost }(\$ / \text { unit } / \text { year }), i . e ., h_{\text {mij }}=h_{\text {mij }}^{f}+h_{\text {mij }}^{p} \\ h_{r i j}^{p} & \text { Physical holding cost of } i \text { th item for } j \text { th consignee }(\$ / \text { unit } / \text { year }) \\ h_{d i j}^{p} & \text { Physical holding cost of } i \text { th item for } j \text { th consignee in transit }(\$ / \text { unit } / \text { year }) \\ \alpha_{i j} & \text { Fraction of invoice's time given to the } j \text { th consignee to settle down its payment } \\ \beta_{i j} & \text { for } i \text { th item (interest-free) } \\ & \text { Fraction of invoice's time given to the } j \text { th consignee to settle down its payment } \\ I_{v i j} & \text { for } i \text { th item (interest-charges }) \\ I_{b i j} & \text { Consignor's investment interest rate of } i \text { th item for } j \text { th consignee }(\% / \text { year }) \\ c_{b i j} & \text { Investment interest rate of } j \text { th consignee for } i \text { th item }(\% / \text { year }) \\ c_{c i j} & \text { Consignor's selling price of } i \text { th finished item for } j \text { th consignee } \\ c_{t i j} & \text { Selling price of } j \text { th consignee for } i \text { th finished item }(\$ / \text { unit }) \\ & \text { Transaction cost of } i \text { th item for } j \text { th consignee }(\$ / \text { transaction })\end{array}$


$T_{i j} \quad$ Cycle length of $i$ th item for $j$ th consignee (year)

$B\left(l_{j}\right) \quad$ Lead time crashing cost for $j$ th consignee (\$/shipment)

\section{Decision variables}

$n_{i j} \quad$ Number of shipments of $i$ th item for $j$ th consignee

$m_{i j} \quad$ Number of payments of $i$ th item for $j$ th consignee

$q_{i j} \quad$ Shipment size of $i$ th item for $j$ th consignee

$k_{i j} \quad$ Number of delayed deliveries of $i$ th item due to the stock capacity of $j$ th consignee

$l_{j} \quad$ Lead time length of $j$ th consignee (year)

\section{Diagram notations}

$B_{1} \quad$ Accumulative sales of $j$ th consignee

$B_{2} \quad$ Profit of $j$ th consignee

$I_{1} \quad$ Interest-free period

$I_{2} \quad$ Interest-charge period

\subsection{Assumptions}

The following assumptions are considered while developing the model.

(1) The demand rate of $i$ th item for $j$ th $(j=1,2,3, \ldots, y)$ consignee is assumed to be constant.

(2) The production rate of $i$ th item per year is finite, and it should be greater than the demand rate of the $i$ th item for $j$ th consignee $\left(i . e ., p_{i}>d_{i j}\right.$ ) to avoid shortages.

(3) The system inventory is continuously reviewed, and the shortage is not allowed.

(4) The cycle time is common for both the consignor and consignee.

(5) The holding cost of the consignor is divided into two parts, namely financial and physical. Therefore, consignor's holding cost of the $i$ th item for the $j$ th consignee, $h_{m i j}=h_{m i j}^{f}+h_{m i j}^{p}$, unit holding cost of the $i$ th item for the $j$ th consignee in transit, $h_{d i j}=h_{d i j}^{p}+h_{m i j}^{f}$, and consignee's unit holding cost of the $i$ th item for the $j$ th consignee, $h_{r i j}=h_{r i j}^{p}+h_{r i j}^{f}$ (refer, [37]).

(6) The consignee incurs only the physical holding cost for $i$ th item.

(7) For the $j$ th consignee, the lead time $l_{j}$ consists of $n_{j}$ components which are mutually independent. The $k$ th component has a minimum duration $m_{j, k}$, normal duration $n_{j, k}$ and a crashing cost per unit time $e_{j, k}$ and assume that $e_{j, 1} \leq e_{j, 2} \leq \ldots \leq e_{j, n_{i j}}$. The lead time components are to be crashed one at a time beginning from the least component of $e_{i}$ and so on.

(8) Let $l_{j, 0}=\sum_{k=1}^{n_{i j}} n_{j, k}$ and $l_{j, f}$ is the length of the lead time components $1,2,3, \ldots, f$ crashed to their minimum duration, then expression of $l_{j, f}$ is given by $l_{j, f}=l_{j, 0}-\sum_{j=1}^{f}\left(n_{j, k}-m_{j, k}\right)$, where $f=1,2, \ldots, n_{i j}$ and crashing cost for the lead time per cycle is given by (see, for instance, [27])

$$
B\left(l_{j}\right)=e_{j, f}\left(l_{j, f-1}-l_{j}\right)+\sum_{k=1}^{f-1} e_{j, k}\left(n_{j, k}-m_{j, k}\right), l_{j} \in\left[l_{j, f}, l_{j, f-1}\right] .
$$

\section{Mathematical Model}

In this section, a trapezoidal fuzzy number and signed distance method are provided for a preliminary purpose, then a mathematical formulation is developed, including four cases. Basic costs related to inventory and production are unpredictable due to various factors, i.e., inflation, the global energy crisis, fuel prices, and oil prices. Failing to consider these unforeseen circumstances results in an unstable supply chain model. For this reason, all the specific costs associated with the consignor and the consignee are considered to be fuzzy costs (Trapezoidal fuzzy number) in the proposed model. The signed distance method is used to solve fuzzy parameters. 


\subsection{Trapezoidal fuzzy number}

The fuzzy number $\tilde{t}$ is said to be a non-negative trapezoidal fuzzy number $\left(t_{1}, t_{2}, t_{3}, t_{4}\right)$ of $t_{i}$ such that $t_{1}<t_{2}<t_{3}<t_{4}$. The membership function of trapezoidal fuzzy number is given by

$$
\mu_{d}(x)= \begin{cases}0, & x \leq t_{1} \\ \mathcal{B}(x)=\frac{x-t_{1}}{t_{2}-t_{1}}, & t_{1} \leq x \leq t_{2} \\ 1, & t_{2} \leq x \leq t_{3} \\ \mathcal{K}(x)=\frac{x-t_{4}}{t_{3}-t_{4}}, & t_{3} \leq x \leq t_{4} \\ 0, & x \geq t_{4}\end{cases}
$$

where, $t_{1}=$ lower limit, $t_{2}=$ lower mode, $t_{3}=$ upper mode and $t_{4}=$ upper limit of the fuzzy number $\tilde{t}$. We represent the trapezoidal fuzzy number as $\tilde{t}=\left(t-\varphi_{1}, t-\varphi_{2}, t+\varphi_{3}, t+\varphi_{4}\right)$, where $\varphi_{i}, i=1,2,3,4$ are arbitrary positive numbers with the restriction $t>\varphi_{1}>\varphi_{2}, \varphi_{3}<\varphi_{4}$. For the trapezoidal fuzzy number $\tilde{t}=\left(t_{1}, t_{2}, t_{3}, t_{4}\right)$, the left and right $\lambda$ cuts of $\tilde{t}$ are respectively given by $\tilde{t}_{L}(\lambda)=t_{1}+\left(t_{2}-t_{1}\right) \lambda$ and $\tilde{t}_{U}(\lambda)=t_{4}-\left(t_{4}-t_{3}\right) \lambda$.

\subsection{Signed distance method}

For any $t \in R, d(t, 0)=t$ is named as the signed distance from $t$ to 0 . If $t>0$, then the distance from $t$ to 0 is $t=d(t, 0)$; if $t<0$, the distance from $t$ to 0 is $-t=-d(t, 0)$. Therefore, $d(t, 0)=t$ is known as the signed distance from $t$ to 0 .

For the fuzzy set $\tilde{t} \in R^{+}, 0 \leq \lambda \leq 1$, the following expression can be obtained as $\tilde{F}=\cup_{0 \leq \lambda \leq 1} \tilde{F}_{\lambda}=$ $\cup_{0 \leq \lambda \leq 1}\left[L_{\lambda}, R_{\lambda}\right]$. The signed distance of the interval $\left[L_{\lambda}, R_{\lambda}\right]$ measured from the origin 0 is given by $d\left(\left[L_{\lambda}, R_{\lambda}\right], \tilde{0}\right)=\frac{\left(\tilde{F}_{L}(\lambda)+\tilde{F}_{U}(\lambda)\right)}{2}$. For the fuzzy number $\tilde{F} \in R^{-}$, the proposed defuzzification methods $d(\tilde{F}, 0)$ (the distance from $\tilde{F}$ to 0 ) is written as

$$
\begin{aligned}
d_{0}(\tilde{F}, \tilde{0}) & =\int_{0}^{1} d\left(\tilde{F}_{\lambda}, \tilde{0}\right) \mathrm{d} \lambda=\int_{0}^{1} d\left(\left[L_{\lambda}, R_{\lambda}\right], \tilde{0}\right) \mathrm{d} \lambda=\frac{1}{2} \int_{0}^{1}\left\{\tilde{F}_{L}(\lambda)+\tilde{F}_{U}(\lambda)\right\} \mathrm{d} \lambda \\
& =\frac{1}{2} \int_{0}^{1}\left[t_{1}+\left(t_{2}-t_{1}\right) \lambda+t_{4}-\left(t_{4}-t_{3}\right) \lambda\right] \mathrm{d} \lambda=\frac{1}{4}\left[t_{1}+t_{2}+t_{3}+t_{4}\right]
\end{aligned}
$$

\subsection{Mathematical formulation}

All four cases in this study consider the model between a single consignor and multiple consignees with multi-item based on the CS policy.

The cost associated with CS policy model are considered as the trapezoidal fuzzy number 4.1, which are given in the following:

Set-up cost: $\tilde{S}_{v i}=\left(S_{v i}-\varphi_{S_{v i 1}}, S_{v i}-\varphi_{S_{v i 2}}, S_{v i}+\varphi_{S_{v i 3}}, S_{v i}+\varphi_{S_{v i 4}}\right)$,

Selling price: $\tilde{c}_{c i j}=\left(c_{c i j}-\varphi_{c_{c i j 1}}, c_{c i j}-\varphi_{c_{c i j 2}}, c_{c i j}+\varphi_{c_{c i j 3}}, c_{c i j}+\varphi_{c_{c i j 4}}\right)$,

Transaction cost: $\tilde{c}_{t i j}=\left(c_{t i j}-\varphi_{c_{t i j 1}}, c_{t i j}-\varphi_{c_{t i j 2}}, c_{t i j}+\varphi_{c_{t i j 3}}, c_{t i j}+\varphi_{c_{t i j 4}}\right)$,

Order cost: $\tilde{O}_{b i j}=\left(O_{b i j}-\varphi_{O_{b i j 1}}, O_{b i j}-\varphi_{O_{b i j 2}}, O_{b i j}+\varphi_{O_{b i j 3}}, O_{b i j}+\varphi_{O_{b i j 4}}\right)$,

Production cost: $\tilde{c}_{p r i}=\left(c_{p r i}-\varphi_{c_{p r i 1}}, c_{p r i}-\varphi_{c_{p r i 2}}, c_{p r i}+\varphi_{c_{p r i 3}}, c_{p r i}+\varphi_{c_{p r i 4}}\right)$,

Consignor's selling price: $\tilde{c}_{b i j}=\left(c_{b i j}-\varphi_{c_{b i j 1}}, c_{b i j}-\varphi_{c_{b i j} 2}, c_{b i j}+\varphi_{c_{b i j 3}}, c_{b i j}+\varphi_{c_{b i j 4}}\right)$,

Transit physical holding cost: $\tilde{h}_{d i j}^{p}=\left(h_{d i j}^{p}-\varphi_{h_{d i j 1}^{p}}, h_{d i j}^{p}-\varphi_{h_{d i j 2}^{p}}, h_{d i j}^{p}+\varphi_{h_{d i j 3}^{p}}, h_{d i j}^{p}+\varphi_{h_{d i j 4}^{p}}\right)$,

Consignor's raw material purchasing cost: $\tilde{c}_{p i}=\left(c_{p i}-\varphi_{c_{p i 1}}, c_{p i}-\varphi_{c_{p i 2}}, c_{p i}+\varphi_{c_{p i 3}}, c_{p i}+\varphi_{c_{p i 4}}\right)$,

Consignee's physical holding cost: $\tilde{h}_{r i j}^{p}=\left(h_{r i j}^{p}-\varphi_{h_{r i j 1}^{p}}, h_{r i j}^{p}-\varphi_{h_{r i j 2}^{p}}, h_{r i j}^{p}+\varphi_{h_{r i j 3}^{p}}^{p}, h_{r i j}^{p}+\varphi_{h_{r i j 4}^{p}}\right)$,

Consigor's financial holding cost: $\tilde{h}_{m i j}^{f}=\left(h_{m i j}^{f}-\varphi_{h_{m i j 1}^{f}}, h_{m i j}^{f}-\varphi_{h_{m i j 2}^{f}}, h_{m i j}^{f}+\varphi_{h_{m i j 3}^{f}}, h_{m i j}^{f}+\varphi_{h_{m i j 4}^{f}}\right)$, and

Consigor's physical holding cost: $\tilde{h}_{m i j}^{p}=\left(h_{m i j}^{p}-\varphi_{h_{m i j 1}^{p}}^{p}, h_{m i j}^{p}-\varphi_{h_{m i j 2}^{p}}^{p}, h_{m i j}^{p}+\varphi_{h_{m i j 3}^{p}}^{p}, h_{m i j}^{p}+\varphi_{h_{m i j 4}^{p}}^{p}\right)$, 
where $\varphi_{S_{v i c}}, \varphi_{O_{b i j c}}, \varphi_{h_{m i j c}^{f}}, \varphi_{h_{m i j c}^{p}}, \varphi_{h_{d i j c}^{p}}, \varphi_{h_{r i j c}^{p}}, \varphi_{c_{t i j c}}, \varphi_{c_{p r i c}}, \varphi_{c_{b i c}}, \varphi_{c_{c i c}}$ and $\varphi_{c_{p i c}}, i=1,2,3 ; j=1,2,3$; $c=1,2,3,4$, are arbitrary positive numbers under the following conditions:

$$
\begin{aligned}
& S_{v i}>\varphi_{S_{v i 1}}>\varphi_{S_{v i 2}}, \varphi_{S_{v i 3}}<\varphi_{S_{v i 4}} ; O_{b i j}>\varphi_{O_{b i j 1}}>\varphi_{O_{b i j 2}}, \varphi_{O_{b i j 3}}<\varphi_{O_{b i j 4}} ; h_{m i j}^{f}>\varphi_{h_{m i j 1}^{f}}>\varphi_{h_{m i j 2}^{f}}, \\
& \varphi_{h_{m i j 3}^{f}}<\varphi_{h_{m i j 4}^{f}} ; h_{m i j}^{p}>\varphi_{h_{m i j 1}^{p}}>\varphi_{h_{m i j 2}^{p}}, \varphi_{h_{m i j 3}^{p}}<\varphi_{h_{m i j 4}^{p}} ; h_{d i j}^{p}>\varphi_{h_{d i j 1}^{p}}>\varphi_{h_{d i j 2}^{p}}, \varphi_{h_{d i j 3}^{p}}<\varphi_{h_{d i j 4}^{p}} ; \\
& h_{r i j}^{p}>\varphi_{h_{r i j 1}^{p}}>\varphi_{h_{r i j 2}^{p}}, \varphi_{h_{r i j 3}^{p}}<\varphi_{h_{r i j 4}^{p}} ; c_{t i j}>\varphi_{c_{t i j 1}}>\varphi_{c_{t i j 2}}, \varphi_{c_{t i j 3}}<\varphi_{c_{t i j}} ; c_{p r i}>\varphi_{c_{p r i 1}}>\varphi_{c_{p r i 2} 2}, \\
& \varphi_{c_{p r i 3}}<\varphi_{c_{p r i 4}} ; c_{b i j}>\varphi_{c_{b i j 1}}>\varphi_{c_{b i j 2} 2}, \varphi_{c_{b i j 3}}<\varphi_{c_{b i j 4}} ; c_{c i j}>\varphi_{c_{c i j 1}}>\varphi_{c_{c i j 2} 2}, \varphi_{c_{c i j 3}}<\varphi_{c_{c i j 4}} ; \quad \text { and } \\
& c_{p i}>\varphi_{c_{p i 1}}>\varphi_{c_{p i 2}}, \varphi_{c_{p i 3}}<\varphi_{c_{p i 4}} .
\end{aligned}
$$

The cost formulation of the consignor and consignees are described as follows.

\subsubsection{Consignor's cost formulation}

The costs associated with the consignor for $y$ consignees and $z$ items are derived as following:

Setup cost. Setup cost is the cost of purchasing and maintaining the equipment needed for the production stage before manufacturing the products,

$$
\mathrm{SC}=\sum_{i=1}^{z} \sum_{j=1}^{y} \frac{\tilde{S}_{v i} d_{i j}}{n_{i j} q_{i j}} .
$$

Raw material cost. Spare parts are required to make a finished product, so the cost of purchasing those spare parts (raw materials) is known to be a raw material cost,

$$
\mathrm{RMC}=\sum_{i=1}^{z} \sum_{j=1}^{y} \gamma_{i} \tilde{c}_{p i} d_{i j} .
$$

Production cost. Production costs refer to the cost of producing or manufacturing an item. Also, this includes direct labour costs, direct material and overhead costs for production,

$$
\mathrm{PC}=\sum_{i=1}^{z} \sum_{j=1}^{y} \tilde{c}_{p r i} d_{i j} .
$$

Lead time crashing cost. Lead time is the interval between when an order is placed to fill the goods and when the order is received. However, to reduce the length of lead time, the crashing cost is used as

$$
\mathrm{LTCC}=\sum_{i=1}^{z} \sum_{j=1}^{y} \frac{B\left(l_{j}\right) d_{i j}}{q_{i j}} .
$$

\subsubsection{Consignee's cost formulation}

The costs associated with $y$ consignees for $z$ items are derived as follows:

Purchasing cost. Purchase cost refers to the cost of purchasing products from the consignor,

$$
\mathrm{PRC}=\sum_{i=1}^{z} \sum_{j=1}^{y} \tilde{c}_{b_{i j}} d_{i j} .
$$


Ordering cost. The cost required by $y$ consignees to process the order from the consignor is said to be an ordering cost,

$$
\mathrm{OC}=\sum_{i=1}^{z} \sum_{j=1}^{y} \frac{\tilde{O}_{b i j} d_{i j}}{q_{i j}}
$$

Transaction cost. The commission paid by $y$ consignees for transaction per cycle is calculated as

$$
\mathrm{TRC}=\sum_{i=1}^{z} \sum_{j=1}^{y} \frac{m_{i j} \tilde{c}_{t i j} d_{i j}}{n_{i j} q_{i j}}
$$

The total cost of the supply chain (without inventory holding cost of the consignor and $y$ consignees) is derived by adding equations (4.3)-(4.9).

$$
\begin{aligned}
C_{\text {total }} & =\mathrm{SC}+\mathrm{RMC}+\mathrm{PC}+\mathrm{LTCC}+\mathrm{PRC}+\mathrm{OC}+\mathrm{TRC} \\
C_{\text {total }} & =\sum_{i=1}^{z} \sum_{j=1}^{y}\left(\gamma_{i} \tilde{c}_{p i}+\tilde{c}_{p r i}+\tilde{c}_{b i j}\right) d_{i j}+\left(\tilde{S}_{v i}+n_{i j} \tilde{O}_{b i j}+m_{i j} \tilde{c}_{t i j}+n_{i j} B\left(l_{j}\right)\right) \frac{d_{i j}}{n_{i j} q_{i j}} .
\end{aligned}
$$

Case 1. CS policy with NDIP - NDIS under CLT $\left(\boldsymbol{h}_{\boldsymbol{m i j}}^{\boldsymbol{p}}>\boldsymbol{h}_{\boldsymbol{r i j}}^{\boldsymbol{p}}\right)$. The consignor produces $q_{i j}$ of items in each $n_{i j}$ batches within cycle with fixed setup cost $S_{v i}$ at finite production rate $p_{i}$. In order to avoid the shock out, the production rate is assumed to be greater than the demand rate. The consignor utilizes the consignee's warehouse space to store the manufactured items; this seems to be more advantageous for the consignor to keep fewer items in the warehouse. Moreover, there is an advantage for the consignee by holding the maximum stock level to avoid stockouts. The inventory pattern of the consignor, transit, consignees and financial behaviour of $y$ consignees can be seen in Figure 1, and the average inventory of the system is calculated as

$$
I_{\mathrm{cS}}=\sum_{i=1}^{z} \sum_{j=1}^{y} q_{i j}\left(\frac{n_{i j}}{2}-\frac{n_{i j} d_{i j}}{2 p_{i}}+\frac{d_{i j}}{p_{i}}\right)+d_{i j} l_{j}
$$

The average inventory of $y$ consignees are derived by dividing the area $\sum_{i=1}^{z} \sum_{j=1}^{y} q_{i j}^{2}\left(\frac{n_{i j}}{2 p_{i}}-\frac{n_{i j}^{2}}{2 p_{i}}+\frac{n_{i j}^{2}}{2 d_{i j}}\right)$ by the cycle time $\sum_{i=1}^{z} \sum_{j=1}^{y} \frac{n_{i j} q_{i j}}{d_{i j}}=\sum_{i=1}^{z} \sum_{j=1}^{y} T_{i j}$, that is,

$$
I_{\text {consignee }}=\sum_{i=1}^{z} \sum_{j=1}^{y} \frac{q_{i j}^{2}\left(\frac{n_{i j}}{2 p_{i}}-\frac{n_{i j}^{2}}{2 p_{i}}+\frac{n_{i j}^{2}}{2 d_{i j}}\right)}{T_{i j}}=\sum_{i=1}^{z} \sum_{j=1}^{y} \frac{d_{i j}}{n_{i j} q_{i j}} \times q_{i j}^{2}\left(\frac{n_{i j}}{2 p_{i}}-\frac{n_{i j}^{2}}{2 p_{i}}+\frac{n_{i j}^{2}}{2 d_{i j}}\right) .
$$

The average inventory in transit is calculated as.

$$
I_{\text {transit }}=\sum_{i=1}^{z} \sum_{j=1}^{y} n_{i j} q_{i j} l_{j} \times \frac{1}{T_{i j}}=\sum_{i=1}^{z} \sum_{j=1}^{y} \frac{d_{i j}}{n_{i j} q_{i j}} \times n_{i j} q_{i j} l_{j}=\sum_{i=1}^{z} \sum_{j=1}^{y} d_{i j} l_{j} .
$$

The average inventory of the consignor $I_{\text {consignor }}$ is derived by subtracting $I_{\text {consignee }}$ and $I_{\text {transit }}$ from the system average inventory $I_{\mathrm{cs}}$.

$$
I_{\text {consignor }}=I_{\mathrm{cs}}-I_{\text {consignee }}-I_{\text {transit }}=\sum_{i=1}^{z} \sum_{j=1}^{y} \frac{q_{i j} d_{i j}}{2 p_{i}}
$$




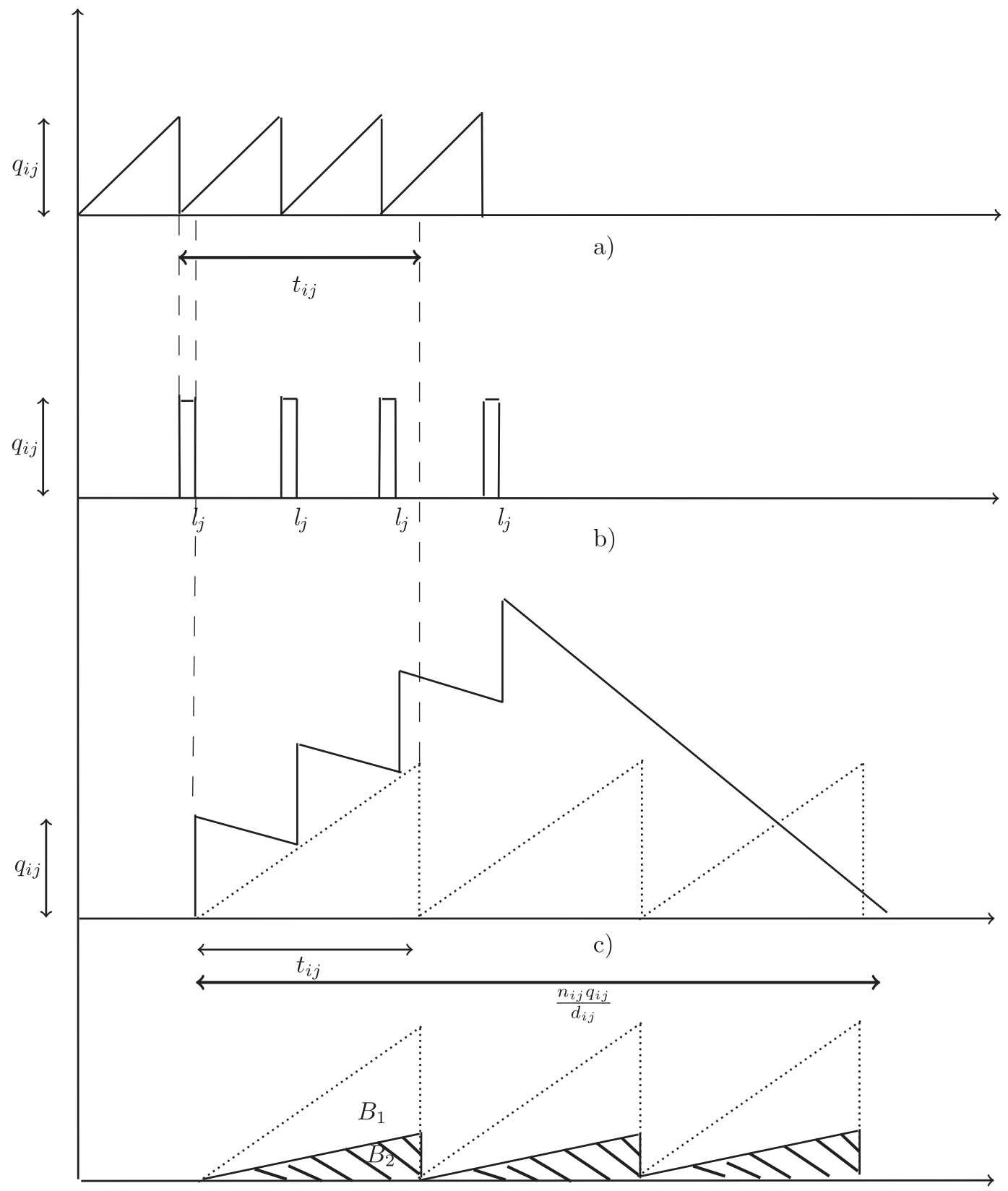

d)

FiguRE 1. Inventory pattern of consignment stock policy with no delay in payment and no delay in shipment under controllable lead time (Case 1). (a) Consignor inventory. (b) Transit inventory. (c) Inventory of $j$ th consignee. (d) Financial behaviour of $j$ th consignee. 
therefore, the physical holding cost of the consignor for $y$ consignees are obtained as

$$
\sum_{i=1}^{z} \sum_{j=1}^{y} \tilde{h}_{m i j}^{p} \frac{q_{i j} d_{i j}}{2 p_{i}} .
$$

The financial holding cost of the consignor is formulated as (see, for instance, [39])

$$
\sum_{i=1}^{z} \sum_{j=1}^{y} \tilde{h}_{m i j}^{f}\left(\frac{\left(m_{i j}+1\right) n_{i j} q_{i j}}{2 m_{i j}}-\left(n_{i j}-1\right) \frac{q_{i j} d_{i j}}{2 p_{i}}\right)
$$

where, $\tilde{h}_{m i j}^{f}=\tilde{c}_{b i j} I_{v i j}$. The physical holding cost of $y$ consignees are derived as

$$
\sum_{i=1}^{z} \sum_{j=1}^{y} \tilde{h}_{r i j}^{p}\left(\frac{n_{i j} q_{i j}}{2}-\left(n_{i j}-1\right) \frac{q_{i j} d_{i j}}{2 p_{i}}\right)
$$

and the transit holding cost is given as

$$
\sum_{i=1}^{z} \sum_{j=1}^{y}\left(\tilde{h}_{d i j}^{p}+\tilde{h}_{m i j}^{f}\right) d_{i j} l_{j}
$$

The total cost of the supply chain with $y$ consignees for $z$ items are calculated by adding the equations (4.10), (4.15)-(4.18).

$$
\begin{aligned}
\tilde{C}_{1}\left(m_{i j}, n_{i j}, q_{i j}, l_{j}\right)= & \sum_{i=1}^{z} \sum_{j=1}^{y}\left(\gamma_{i} \tilde{c}_{p i}+\tilde{c}_{p r i}+\tilde{c}_{b i j}\right) d_{i j}+\left(\tilde{S}_{v i}+n_{i j} \tilde{O}_{b i j}+m_{i j} \tilde{c}_{t i j}+n_{i j} B\left(l_{j}\right)\right) \frac{d_{i j}}{n_{i j} q_{i j}} \\
& +\tilde{h}_{m i j}^{f}\left(\frac{\left(m_{i j}+1\right) n_{i j} q_{i j}}{2 m_{i j}}-\left(n_{i j}-1\right) \frac{q_{i j} d_{i j}}{2 p_{i}}\right)+\left(\tilde{h}_{m i j}^{p}+\tilde{h}_{m i j}^{f}\right) \frac{q_{i j} d_{i j}}{2 p_{i}} \\
& +\tilde{h}_{r i j}^{p}\left(\frac{n_{i j} q_{i j}}{2}-\left(n_{i j}-1\right) \frac{q_{i j} d_{i j}}{2 p_{i}}\right)+\left(\tilde{h}_{d i j}^{p}+\tilde{h}_{m i j}^{f}\right) d_{i j} l_{j} .
\end{aligned}
$$

The revenue of the consignor is obtained as

$$
\tilde{R}_{\text {consignor }}^{1}=\sum_{i=1}^{z} \sum_{j=1}^{y} \tilde{c}_{b i j} d_{i j}
$$

and the revenue of $y$ consignees for $z$ items are obtained by adding the selling price and investment interest rate of $y$ consignees for $z$ items.

$$
\tilde{R}_{\text {consignee }}^{1}=\sum_{i=1}^{z} \sum_{j=1}^{y} \tilde{c}_{c i j}\left(d_{i j}+I_{b i j} \frac{n_{i j} q_{i j}}{2 m_{i j}}\right) .
$$

Then the total revenue of the supply chain is calculated by adding the equations (4.20) and (4.21), that is,

$$
\tilde{R}_{\text {total }}^{1}\left(m_{i j}, n_{i j}, q_{i j}\right)=\sum_{i=1}^{z} \sum_{j=1}^{y} \tilde{c}_{b i j} d_{i j}+\tilde{c}_{c i j}\left(d_{i j}+I_{b i j} \frac{n_{i j} q_{i j}}{2 m_{i j}}\right) .
$$

Hence, the annual profit function $\tilde{P}_{1}\left(m_{i j}, n_{i j}, q_{i j}, l_{j}\right)$ for case 1 can be written as

$$
\operatorname{Max} \tilde{P}_{1}\left(m_{i j}, n_{i j}, q_{i j}, l_{j}\right)=\tilde{R}_{\text {total }}^{1}\left(m_{i j}, n_{i j}, q_{i j}\right)-\tilde{C}_{1}\left(m_{i j}, n_{i j}, q_{i j}, l_{j}\right)
$$




$$
\begin{aligned}
\operatorname{Max} \tilde{P}_{1}\left(m_{i j}, n_{i j}, q_{i j}, l_{j}\right)= & \sum_{i=1}^{z} \sum_{j=1}^{y} \tilde{c}_{b i j} d_{i j}+\tilde{c}_{c i j}\left(d_{i j}+I_{b i j} \frac{n_{i j} q_{i j}}{2 m_{i j}}\right)-\left(\left(\gamma_{i} \tilde{c}_{p i}+\tilde{c}_{p r i}+\tilde{c}_{b i j}\right) d_{i j}\right. \\
& +\left(\tilde{S}_{v i}+n_{i j} \tilde{O}_{b i j}+m_{i j} \tilde{c}_{t i j}+n_{i j} B\left(l_{j}\right)\right) \frac{d_{i j}}{n_{i j} q_{i j}} \\
& +\tilde{h}_{m i j}^{f}\left(\frac{\left(m_{i j}+1\right) n_{i j} q_{i j}}{2 m_{i j}}-\left(n_{i j}-1\right) \frac{q_{i j} d_{i j}}{2 p_{i}}\right)+\left(\tilde{h}_{m i j}^{p}+\tilde{h}_{m i j}^{f}\right) \\
& \left.\times \frac{q_{i j} d_{i j}}{2 p_{i}}+\tilde{h}_{r i j}^{p}\left(\frac{n_{i j} q_{i j}}{2}-\left(n_{i j}-1\right) \frac{q_{i j} d_{i j}}{2 p_{i}}\right)+\left(\tilde{h}_{d i j}^{p}+\tilde{h}_{m i j}^{f}\right) d_{i j} l_{j}\right)
\end{aligned}
$$

subject to

$$
\begin{gathered}
\left(n_{i j} q_{i j}-\left(n_{i j}-1\right) q_{i j} \frac{d_{i j}}{p_{i}}\right) \leq I_{\max }, \\
q_{i j}>0,
\end{gathered}
$$

$m_{i j}, n_{i j}$ and $l_{j}$ are positive integers.

Case 2. CS policy with DIP - NDIS under CLT $\left(\boldsymbol{h}_{\boldsymbol{m i j}}^{p}>\boldsymbol{h}_{\boldsymbol{r i j}}^{\boldsymbol{p}}\right)$. In this case, the consignor offers the allowable payment delay to the consignee under the CS policy, i.e., the consignee pays the invoice amount to the consignor by the end of the permissible period $\tau_{i j}=t_{i j}+\alpha_{i j} t_{i j}$, where $\alpha_{i j} t_{i j}$ is delay period offered by the consignor without interest. Sometimes, in reality, the consignee may not pay the invoice amount within the delay period $\alpha_{i j} t_{i j}$. Therefore, the consignee may pay the invoice amount with interest charges by the end of the period $\delta_{i j}=t_{i j}+\alpha_{i j} t_{i j}+\beta_{i j} \tau_{i j}$, where $\beta_{i j}>0$. The inventory pattern for this case is given by Figure 2, and the system inventory is the same as in the case 1 . The opportunity loss of the consignor is written as (see, for instance, [39])

$$
\sum_{i=1}^{z} \sum_{j=1}^{y} \tilde{h}_{m i j}^{f}\left(\frac{\left(m_{i j}+1+2 \alpha_{i j}+2 \beta_{i j}\left(1+\alpha_{i j}\right)\right) n_{i j} q_{i j}}{2 m_{i j}}-\left(n_{i j}-1\right) \frac{q_{i j} d_{i j}}{2 p_{i}}\right) .
$$

The consignee pays the invoice amount by the end of $\delta_{i j}$ period, therefore the interest charges for the extra delay by $\beta_{i j} \tau_{i j}$, which incurs the cost of $\sum_{i=1}^{z} \sum_{j=1}^{y}\left(\delta_{i j}-\tau_{i j}\right) c_{b i j} I_{v i j} d_{i j} T_{i j}$, where $\sum_{i=1}^{z} \sum_{j=1}^{y} T_{i j}=$ $\sum_{i=1}^{z} \sum_{j=1}^{y} \frac{\beta_{i j}\left(1+\alpha_{i j}\right) n_{i j} q_{i j}}{m_{i j} d_{i j}}$. The total cost for case 2 is obtained by adding (4.10), (4.15), (4.17), (4.18) and (4.25).

$$
\begin{aligned}
\tilde{C}_{2}\left(m_{i j}, n_{i j}, q_{i j}, l_{j}\right) \\
=\sum_{i=1}^{z} \sum_{j=1}^{y}\left(\left(\gamma_{i} \tilde{c}_{p i}+\tilde{c}_{p r i}+\tilde{c}_{b i j}\right) d_{i j}+\left(\tilde{S}_{v i}+n_{i j} \tilde{O}_{b i j}+m_{i j} \tilde{c}_{t i j}+n_{i j} B\left(l_{j}\right)\right) \frac{d_{i j}}{n_{i j} q_{i j}}\right. \\
\quad+\left(\tilde{h}_{m i j}^{p}+\tilde{h}_{m i j}^{f}\right) \frac{q_{i j} d_{i j}}{2 p_{i}}+\tilde{h}_{m i j}^{f}\left(\frac{\left(m_{i j}+1+2 \alpha_{i j}+2 \beta_{i j}\left(1+\alpha_{i j}\right)\right) n_{i j} q_{i j}}{2 m_{i j}}-\left(n_{i j}-1\right) \frac{q_{i j} d_{i j}}{2 p_{i}}\right) \\
\left.\quad+\tilde{h}_{r i j}^{p}\left(\frac{n_{i j} q_{i j}}{2}-\left(n_{i j}-1\right) \frac{q_{i j} d_{i j}}{2 p_{i}}\right)+\tilde{c}_{b i} I_{v i j}\left(\frac{\beta_{i j}\left(1+\alpha_{i j}\right) n_{i j} q_{i j}}{m_{i j}}\right)+\left(\tilde{h}_{d i j}^{p}+\tilde{h}_{m i j}^{f}\right) d_{i j} l_{j}\right) .
\end{aligned}
$$

The consignor's revenue is adding obtained by selling cost of the $z$ items to the $y$ consignees and the interest charged for unsettled balances, which is written as

$$
\tilde{R}_{\text {consignor }}^{2}=\sum_{i=1}^{z} \sum_{j=1}^{y} c_{b i j}\left(d_{i j}+I_{v i j} \frac{\beta_{i j}\left(1+\alpha_{i j}\right) n_{i j} q_{i j}}{m_{i j}}\right) .
$$




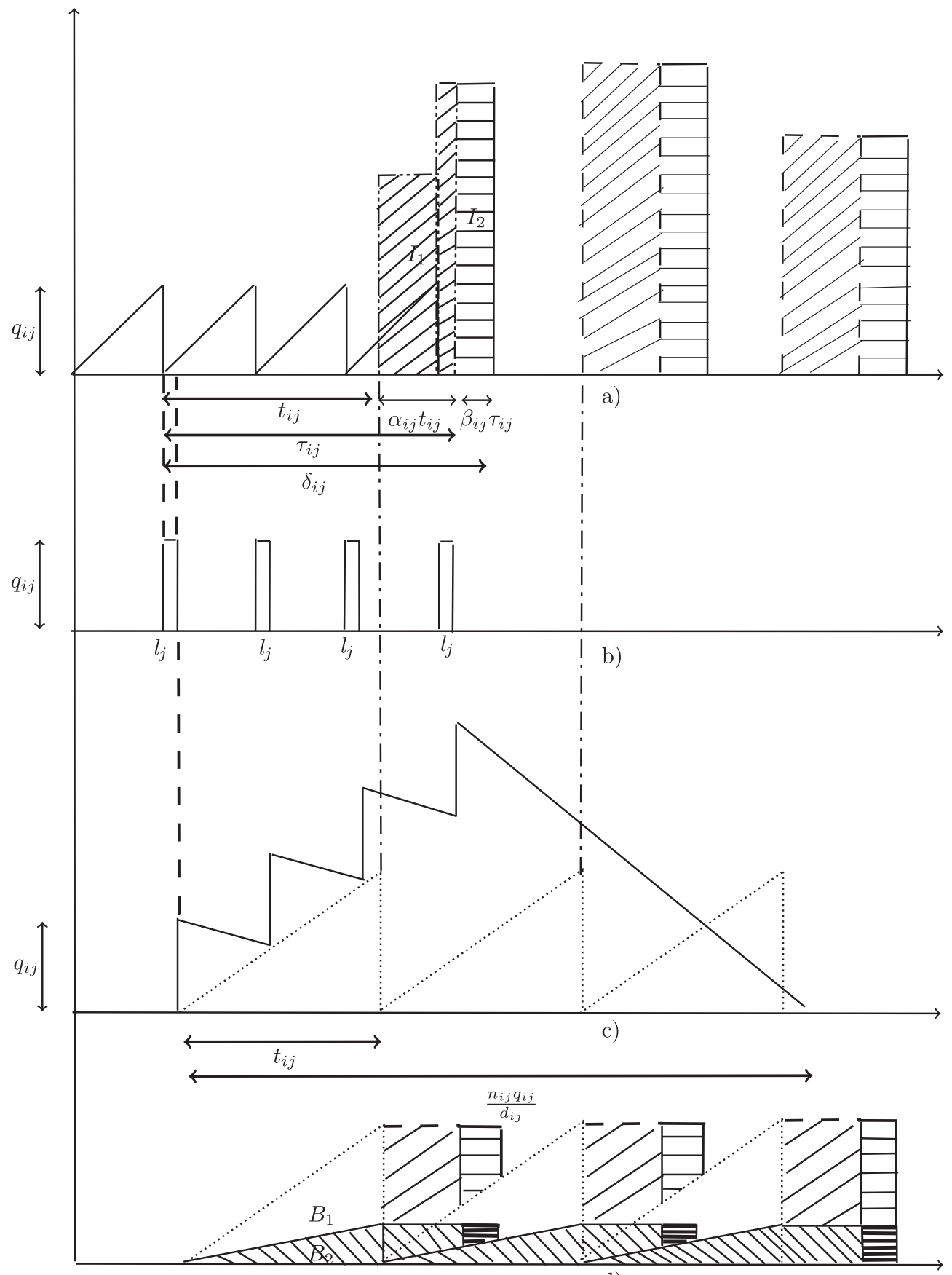

d)

FIGURE 2. Inventory pattern of CS policy with delay in payment and no delay in shipment under controllable lead time (Case 2). (a) Consignor inventory. (b) Transit inventory. (c) Inventory of $j$ th consignee. (d) Financial behaviour of $j$ th consignee. 
Similarly, the revenue of $y$ consignees is obtained by adding sales and investment (i.e.,)

$$
\tilde{R}_{\text {consignee }}^{2}=\sum_{i=1}^{z} \sum_{j=1}^{y} c_{c i j}\left(d_{i j}+I_{b i j} \frac{\left(2 \alpha_{i j}+1+2 \beta_{i j}\left(1+\alpha_{i j}\right)\right) n_{i j} q_{i j}}{2 m_{i j}}\right) .
$$

Therefore, the total revenue is calculated by adding (4.27) and (4.28).

$$
\begin{aligned}
\tilde{R}_{\text {total }}^{2}\left(m_{i j}, n_{i j}, q_{i j}\right)= & \sum_{i=1}^{z} \sum_{j=1}^{y} c_{b i j}\left(d_{i j}+I_{v i j} \frac{\beta_{i j}\left(1+\alpha_{i j}\right) n_{i j} q_{i j}}{m_{i j}}\right) \\
& +c_{c i j}\left(d_{i j}+I_{b i j} \frac{\left(2 \alpha_{i j}+1+2 \beta_{i j}\left(1+\alpha_{i j}\right)\right) n_{i j} q_{i j}}{2 m_{i j}}\right) .
\end{aligned}
$$

Hence, the annual profit function $\tilde{P}_{2}\left(m_{i j}, n_{i j}, q_{i j}, l_{j}\right)$ for case 2 is calculated by subtracting the total cost (4.26) from the total revenue (4.29) of the supply chain.

$$
\begin{aligned}
\operatorname{Max} \tilde{P}_{2}\left(m_{i j}, n_{i j}, q_{i j}, l_{j}\right)= & \tilde{R}_{\text {total }}^{2}\left(m_{i j}, n_{i j}, q_{i j}\right)-\tilde{C}_{2}\left(m_{i j}, n_{i j}, q_{i j}, l_{j}\right) \\
\operatorname{Max} \tilde{P}_{2}\left(m_{i j}, n_{i j}, q_{i j}, l_{j}\right)= & \sum_{i=1}^{z} \sum_{j=1}^{y} \tilde{c}_{b i j}\left(d_{i j}+I_{v i j} \frac{\beta_{i j}\left(1+\alpha_{i j}\right) n_{i j} q_{i j}}{m_{i j}}\right)+\tilde{c}_{c i j}\left(d_{i j}+I_{b i j}\left(2 \alpha_{i j}+1\right.\right. \\
& \left.\left.+2 \beta_{i j}\left(1+\alpha_{i j}\right)\right) \times \frac{n_{i j} q_{i j}}{2 m_{i j}}\right)-\left(\left(\gamma_{i} \tilde{c}_{p i}+\tilde{c}_{p r i}+\tilde{c}_{b i j}\right) d_{i j}\right. \\
& +\left(\tilde{S}_{v i}+n_{i j} \tilde{O}_{b i j}+m_{i j} \tilde{c}_{t i j}+n_{i j} B\left(l_{j}\right)\right) \frac{d_{i j}}{n_{i j} q_{i j}}+\left(\tilde{h}_{m i j}^{p}+\tilde{h}_{m i j}^{f}\right) \frac{q_{i j} d_{i j}}{2 p_{i}} \\
& +\tilde{h}_{m i j}^{f}\left(\frac{\left(m_{i j}+1+2 \alpha_{i j}+2 \beta_{i j}\left(1+\alpha_{i j}\right)\right) n_{i j} q_{i j}}{2 m_{i j}}-\left(n_{i j}-1\right) \frac{q_{i j} d_{i j}}{2 p_{i}}\right) \\
& +\tilde{h}_{r i j}^{p}\left(\frac{n_{i j} q_{i j}}{2}-\left(n_{i j}-1\right) \frac{q_{i j} d_{i j}}{2 p_{i}}\right)+\tilde{c}_{b i} I_{v i j}\left(\frac{\beta_{i j}\left(1+\alpha_{i j}\right) n_{i j} q_{i j}}{m_{i j}}\right) \\
& \left.+\left(\tilde{h}_{d i j}^{p}+\tilde{h}_{m i j}^{f}\right) d_{i j} l_{j}\right)
\end{aligned}
$$

subject to

$$
\begin{gathered}
\left(n_{i j} q_{i j}-\left(n_{i j}-1\right) q_{i j} \frac{d_{i j}}{p_{i}}\right) \leq I_{\max }, \\
q_{i j}>0,
\end{gathered}
$$

$m_{i j}, n_{i j}$ and $l_{j}$ are positive integers.

Case 3. CS policy with NDIP - DIS under CLT $\left(\boldsymbol{h}_{m i j}^{p}<\boldsymbol{h}_{\boldsymbol{r i j}}^{\boldsymbol{p}}\right)$. In this case, the consignor faces the problem of limited storage in the consignee's warehouse. The consignor will not offer any payment delay to the consignee. The inventory system with maximum delayed shipment is given in Figure 3, and the average inventory of the system is calculated as the same as in case 1 . The average inventory of consignee is derived by dividing the area $\frac{q_{i j}^{2}}{2}\left(\frac{n_{i j}}{p_{i}}+\left(\frac{1}{p_{i}}-\frac{1}{d_{i j}}\right)\left(k_{i j}^{2}-n_{i j}^{2}+k_{i j}\right)\right)$ by the cycle time $\frac{n_{i j} q_{i j}}{d_{i j}}=T_{i j}$, where, $k_{i j}=n_{i j}-1$. The calculation is on the following:

$$
I_{\text {consignee }}=\sum_{i=1}^{z} \sum_{j=1}^{y} \frac{d_{i j}}{n_{i j} q_{i j}} \times \frac{q_{i j}^{2}}{2}\left(\frac{n_{i j}}{p_{i}}+\left(\frac{1}{p_{i}}-\frac{1}{d_{i j}}\right)\left(k_{i j}^{2}-n_{i j}^{2}+k_{i j}\right)\right) .
$$




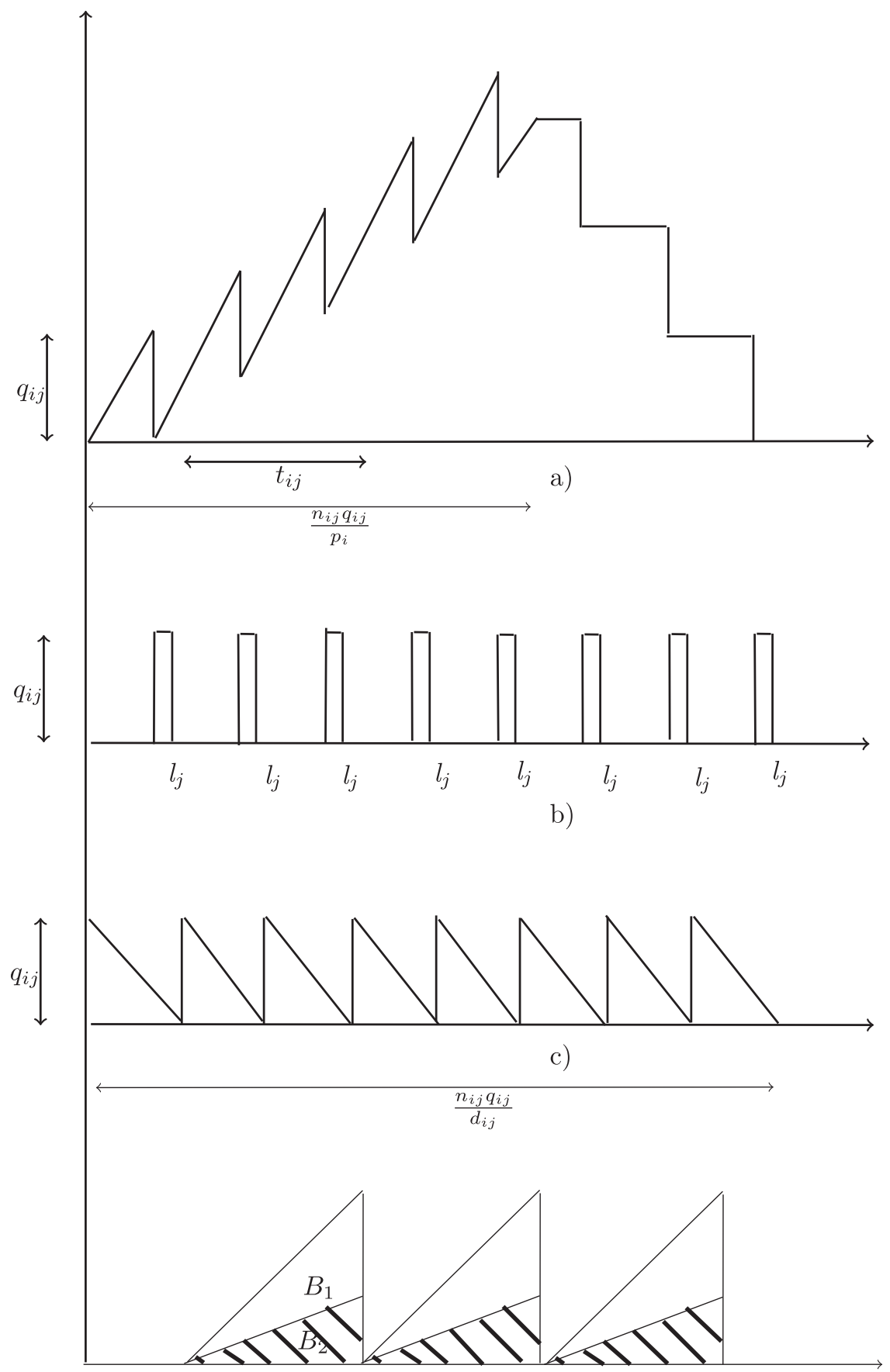

d)

FiguRE 3. Inventory pattern of CS policy with no delay in payment and delay in shipment (Case 3). (a) Consignor inventory. (b) Transit inventory. (c) Inventory of $j$ th consignee. (d) Financial behaviour of $j$ th consignee. 
The average inventory of the consignor $I_{\text {consignor }}$ is equal to the system average inventory $I_{\mathrm{cs}}(4.11)$ minus the consignee's inventory $I_{\text {consignee }}(4.32)$ minus transit inventory $I_{\text {transit }}(4.18)$.

$$
I_{\text {consignor }}=I_{\mathrm{cs}}-I_{\text {consignee }}-I_{\text {transit }}=\sum_{i=1}^{z} \sum_{j=1}^{y} \frac{q_{i j} d_{i j}}{2 p_{i}}+\frac{q_{i j}}{2}\left(1-\frac{d_{i j}}{p_{i}}\right) \frac{k_{i j}^{2}+k_{i j}}{n_{i j}} .
$$

The total cost of the supply chain is derived as

$$
\begin{aligned}
\tilde{C}_{3}\left(m_{i j}, n_{i j}, q_{i j}, k_{i j}, l_{j}\right)= & \sum_{i=1}^{z} \sum_{j=1}^{y}\left(\left(\gamma_{i} \tilde{c}_{p i}+\tilde{c}_{p r i}+\tilde{c}_{b i j}\right) d_{i j}+\left(\tilde{S}_{v i}+n_{i j} \tilde{O}_{b i j}+m_{i j} \tilde{c}_{t i j}+n_{i j} B\left(l_{j}\right)\right) \frac{d_{i j}}{n_{i j} q_{i j}}\right. \\
& +\tilde{h}_{m i j}^{f}\left(\frac{\left(m_{i j}+1\right) n_{i j} q_{i j}}{2 m_{i j}}-\left(n_{i j}-1\right) \frac{q_{i j} d_{i j}}{2 p_{i}}\right)+\left(\tilde{h}_{m i j}^{p}+\tilde{h}_{m i j}^{f}\right) \frac{q_{i j} d_{i j}}{2 p_{i}} \\
& +\tilde{h}_{r i j}^{p}\left(\frac{n_{i j} q_{i j}}{2}-\left(n_{i j}-1\right) \frac{q_{i j} d_{i j}}{2 p_{i}}\right)+\left(\tilde{h}_{m i j}^{p}-\tilde{h}_{r i j}^{p}\right) \\
& \left.\times\left(\frac{q_{i j}\left(p_{i}-d_{i j}\right)}{2 p_{i}}\right)\left(n_{i j}-1\right)+\left(\tilde{h}_{d i j}^{p}+\tilde{h}_{m i j}^{f}\right) d_{i j} l_{j}\right)
\end{aligned}
$$

and the revenue of the consignor and consignee seems to be same as the case 1 . Hence, the annual profit $\tilde{P}_{3}\left(m_{i j}, n_{i j}, q_{i j}, k_{i j}, l_{j}\right)$ can be written as

$$
\begin{aligned}
\operatorname{Max} \tilde{P}_{3}\left(m_{i j}, n_{i j}, q_{i j}, k_{i j}, l_{j}\right)= & \sum_{i=1}^{z} \sum_{j=1}^{y} \tilde{c}_{b i j} d_{i j}+\tilde{c}_{c i j}\left(d_{i j}+I_{b i j} \frac{n_{i j} q_{i j}}{2 m_{i j}}\right)-\left(\left(\gamma_{i} \tilde{c}_{p i}+\tilde{c}_{p r i}+\tilde{c}_{b i j}\right) d_{i j}+\left(\tilde{S}_{v i}\right.\right. \\
& \left.+n_{i j} \tilde{O}_{b i j}+m_{i j} \tilde{c}_{t i j}+n_{i j} B\left(l_{j}\right)\right) \frac{d_{i j}}{n_{i j} q_{i j}} \\
& +\tilde{h}_{m i j}^{f}\left(\frac{\left(m_{i j}+1\right) n_{i j} q_{i j}}{2 m_{i j}}-\left(n_{i j}-1\right) \frac{q_{i j} d_{i j}}{2 p_{i}}\right) \\
& +\left(\tilde{h}_{m i j}^{p}+\tilde{h}_{m i j}^{f}\right) \frac{q_{i j} d_{i j}}{2 p_{i}}+\tilde{h}_{r i j}^{p}\left(\frac{n_{i j} q_{i j}}{2}-\left(n_{i j}-1\right) \frac{q_{i j} d_{i j}}{2 p_{i}}\right)+\left(\tilde{h}_{m i j}^{p}-\tilde{h}_{r i j}^{p}\right) \\
& \left.\times\left(\frac{q_{i j}\left(p_{i}-d_{i j}\right)}{2 p_{i}}\right)\left(n_{i j}-1\right)+\left(\tilde{h}_{d i j}^{p}+\tilde{h}_{m i j}^{f}\right) d_{i j} l_{j}\right)
\end{aligned}
$$

subject to

$$
\begin{gathered}
\left(\left(n_{i j}-k_{i j}\right) q_{i j}-\left(n_{i j}-k_{i j}-1\right) q_{i j} \frac{d_{i j}}{p_{i}}\right) \leq I_{\max }, \\
q_{i j}>0 \\
k_{i j} \leq n_{i j}-1, \\
m_{i j}, n_{i j} \text { and } l_{j} \text { are positive integers. }
\end{gathered}
$$

Case 4. CS policy with DIP - DIS under CLT $\left(\boldsymbol{h}_{\boldsymbol{m i j}}^{\boldsymbol{p}}<\boldsymbol{h}_{\boldsymbol{r i j}}^{\boldsymbol{p}}\right)$. In this case, the consignor offers a payment delay to the consignee and simultaneously, there was a limited storage space in the consignee's warehouse. The inventory of consignor, consignee, transit is depicted in Figure 4. The revenue of the consignor (i.e., Eq. (4.27)) and consignee (i.e., Eq. (4.28)) in case 2 are taken in this case. Then, the consignor's opportunity loss is given in (i.e., Eq. (4.25)). The total cost of the supply chain is calculated as

$$
\tilde{C}_{4}\left(m_{i j}, n_{i j}, q_{i j}, l_{j}\right)=\sum_{i=1}^{z} \sum_{j=1}^{y}\left(\left(\gamma_{i} \tilde{c}_{p i}+\tilde{c}_{p r i}+\tilde{c}_{b i j}\right) d_{i j}+\left(\tilde{S}_{v i}+n_{i j} \tilde{O}_{b i j}+m_{i j} \tilde{c}_{t i j}+n_{i j} B\left(l_{j}\right)\right) \frac{d_{i j}}{n_{i j} q_{i j}}\right.
$$




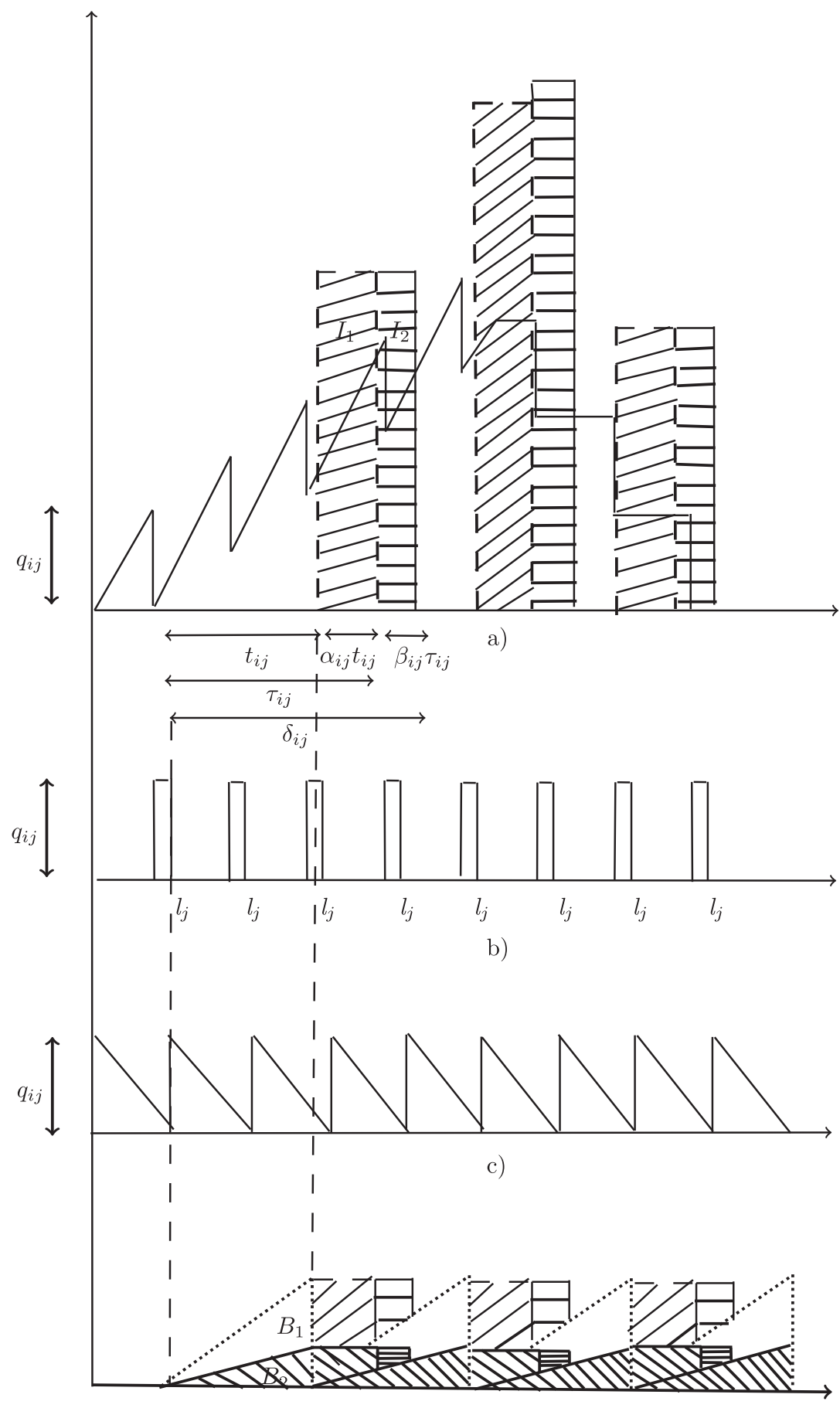

d)

FigURE 4. Inventory pattern of CS policy with delay in payment and delay in shipment under controllable lead time (Case 4). (a) Consignor inventory. (b) Transit inventory. (c) Inventory of $j$ th consignee. (d) Financial behaviour of $j$ th consignee. 


$$
\begin{aligned}
& +\left(\tilde{h}_{m i j}^{p}+\tilde{h}_{m i j}^{f}\right) \frac{q_{i j} d_{i j}}{2 p_{i}}+\tilde{h}_{m i j}^{f}\left(\frac{\left(m_{i j}+1+2 \alpha_{i j}+2 \beta_{i j}\left(1+\alpha_{i j}\right)\right) n_{i j} q_{i j}}{2 m_{i j}}\right. \\
& \left.-\left(n_{i j}-1\right) \frac{q_{i j} d_{i j}}{2 p_{i}}\right)+\tilde{h}_{r i j}^{p}\left(\frac{n_{i j} q_{i j}}{2}-\left(n_{i j}-1\right) \frac{q_{i j} d_{i j}}{2 p_{i}}\right)+\tilde{c}_{b i j} I_{v i j}\left(\frac{\beta_{i j}\left(1+\alpha_{i j}\right) n_{i j} q_{i j}}{m_{i j}}\right) \\
& \left.+\left(\tilde{h}_{m i j}^{p}-\tilde{h}_{r i j}^{p}\right) \times\left(\frac{q_{i j}\left(p_{i}-d_{i j}\right)}{2 p_{i}}\right)\left(n_{i j}-1\right)+\left(\tilde{h}_{d i j}^{p}+\tilde{h}_{m i j}^{f}\right) d_{i j} l_{j}\right)
\end{aligned}
$$

and the total revenue is same as the case 3 . Hence, the annual profit $\tilde{P}_{4}\left(m_{i j}, n_{i j}, q_{i j}, k_{i j}, l_{j}\right)$ can be written as

$$
\begin{aligned}
\operatorname{Max} \tilde{P}_{4}\left(m_{i j}, n_{i j}, q_{i j}, k_{i j}, l_{j}\right)= & \sum_{i=1}^{z} \sum_{j=1}^{y} \tilde{c}_{b i j}\left(d_{i j}+I_{v i j} \frac{\beta_{i j}\left(1+\alpha_{i j}\right) n_{i j} q_{i j}}{m_{i j}}\right) \\
& +\tilde{c}_{c i j}\left(d_{i j}+I_{b i j}\left(2 \alpha_{i j}+1+2 \beta_{i j}\left(1+\alpha_{i j}\right)\right) \frac{n_{i j} q_{i j}}{2 m_{i j}}\right) \\
& -\left(\left(\gamma_{i} \tilde{c}_{p i}+\tilde{c}_{p r i}+\tilde{c}_{b i j}\right) d_{i j}+\left(\tilde{S}_{v i}+n_{i j} \tilde{O}_{b i j}+m_{i j} \tilde{c}_{t i j}+n_{i j} B\left(l_{j}\right)\right) \frac{d_{i j}}{n_{i j} q_{i j}}\right. \\
& +\left(\tilde{h}_{m i j}^{p}+\tilde{h}_{m i j}^{f}\right) \frac{q_{i j} d_{i j}}{2 p_{i}}+\tilde{h}_{m i j}^{f}\left(\frac{\left(m_{i j}+1+2 \alpha_{i j}+2 \beta_{i j}\left(1+\alpha_{i j}\right)\right) n_{i j} q_{i j}}{2 m_{i j}}\right. \\
& \left.-\left(n_{i j}-1\right) \frac{q_{i j} d_{i j}}{2 p_{i}}\right)+\tilde{h}_{r i j}^{p}\left(\frac{n_{i j} q_{i j}}{2}-\left(n_{i j}-1\right) \frac{q_{i j} d_{i j}}{2 p_{i}}\right) \\
& +\tilde{c}_{b i j} I_{v i j}\left(\frac{\beta_{i j}\left(1+\alpha_{i j}\right) n_{i j} q_{i j}}{m_{i j}}\right)+\left(\tilde{h}_{m i j}^{p}-\tilde{h}_{r i j}^{p}\right) \\
& \left.\times\left(\frac{q_{i j}\left(p_{i}-d_{i j}\right)}{2 p_{i}}\right)\left(n_{i j}-1\right)+\left(\tilde{h}_{d i j}^{p}+\tilde{h}_{m i j}^{f}\right) d_{i j} l_{j}\right)
\end{aligned}
$$

subject to

$$
\begin{gathered}
\left(\left(n_{i j}-k_{i j}\right) q_{i j}-\left(n_{i j}-k_{i j}-1\right) q_{i j} \frac{d_{i j}}{p_{i}}\right) \leq I_{\max }, \\
q_{i j}>0 \\
k_{i j} \leq n_{i j}-1,
\end{gathered}
$$

$m_{i j}, n_{i j}$ and $l_{j}$ are positive integers.

\section{DefuzZification methodology}

Defuzzification is the method of generating a quantifiable result in crisp logic, from fuzzy sets and corresponding membership functions (i.e., the process of reducing the fuzzy set to a crisp set or converting the fuzzy quantity to a crisp quantity). There may be situations in which the output of a fuzzy process must be a single scalar quantity as opposed to a fuzzy set. The left and right $\lambda$ cuts of $S_{v i}, O_{b i j}, h_{m i j}^{f}, h_{m i j}^{p}, h_{d i j}^{p}, h_{r i j}^{p}, c_{t i j}, c_{p r i}, c_{b i}, c_{c i}$, and $c_{p i}$ are given below, $\tilde{S}_{L v i}(\lambda)=S_{v i}-\varphi_{S_{v i 1}}+\left(\varphi_{S_{v i 1}}-\varphi_{S_{v i 2}}\right) \lambda ; \tilde{S}_{U v i}(\lambda)=S_{v i}-\varphi_{S_{v i 4}}+\left(\varphi_{S_{v i 4}}-\varphi_{S_{v i 3}}\right) \lambda$, $\tilde{O}_{L b i j}(\lambda)=O_{b i j}-\varphi_{O_{b i j 1}}+\left(\varphi_{O_{b i j 1}}-\varphi_{O_{b i j 2}}\right) \lambda ; \tilde{O}_{U b i j}(\lambda)=O_{b i j}-\varphi_{O_{b i j 4}}+\left(\varphi_{O_{b i j 4}}-\varphi_{O_{b i j 3}}\right) \lambda, \tilde{h}_{L m i j}^{f}(\lambda)=$ $h_{m i j}^{f}-\varphi_{h_{m i j 1}^{f}}+\left(\varphi_{h_{m i j 1}^{f}}-\varphi_{h_{m i j 2}^{f}}\right) \lambda ; \tilde{h}_{U m i j}^{f}(\lambda)=h_{m i j}^{f}-\varphi_{h_{m i j 4}^{f}}+\left(\varphi_{h_{m i j 4}^{f}}-\varphi_{h_{m i j 3}^{f}}\right) \lambda, \tilde{h}_{L m i j}^{p}(\lambda)=h_{m i j}^{p}-$ $\varphi_{h_{m i j 1}^{p}}+\left(\varphi_{h_{m i j 1}^{p}}-\varphi_{h_{m i j 2}^{p}}\right) \lambda ; \tilde{h}_{U m i j}^{p}(\lambda)=h_{m i j}^{p}-\varphi_{h_{m i j 4}^{p}}+\left(\varphi_{h_{m i j 4}^{p}}-\varphi_{h_{m i j 3}^{p}}\right) \lambda, \tilde{h}_{L d i j}^{p}(\lambda)=h_{d i j}^{p}-\varphi_{h_{d i j 1}^{p}}+$ $\left(\varphi_{h_{d i j 1}^{p}}-\varphi_{h_{d i j 2}^{p}}\right) \lambda ; \tilde{h}_{U d i j}^{p}(\lambda)=h_{d i j}^{p}-\varphi_{h_{d i j 4}^{p}}+\left(\varphi_{h_{d i j 4}^{p}}-\varphi_{h_{d i j 3}^{p}}\right) \lambda, \tilde{h}_{L r i j}^{p}(\lambda)=h_{r i j}^{p}-\varphi_{h_{r i j 1}^{p}}+\left(\varphi_{h_{r i j 1}^{p}}-\varphi_{h_{r i j 2}^{p}}\right) \lambda ;$ $\tilde{h}_{U r i j}^{p}(\lambda)=h_{r i j}^{p}-\varphi_{h_{r i j 4}^{p}}+\left(\varphi_{h_{r i j 4}^{p}}-\varphi_{h_{r i j 3}^{p}}\right) \lambda, \tilde{c}_{L t i j}(\lambda)=c_{t i j}-\varphi_{c_{t i j 1}}+\left(\varphi_{c_{t i j 1}}-\varphi_{c_{t i j 2}}\right) \lambda ; \tilde{c}_{U t i j}(\lambda)=c_{t i j}-\varphi_{c_{t i j 4}}+$ 
$\left(\varphi_{c_{t i j 4}}-\varphi_{c_{t i j 3}}\right) \lambda, \tilde{c}_{L p r i}(\lambda)=c_{p r i}-\varphi_{c_{p r i 1}}+\left(\varphi_{c_{p r i 1}}-\varphi_{c_{p r i 2}}\right) \lambda ; \tilde{c}_{U p r i}(\lambda)=c_{p r i}-\varphi_{c_{p r i 4}}+\left(\varphi_{c_{p r i 4}}-\varphi_{c_{p r i 3}}\right) \lambda$, $\tilde{c}_{L b i}(\lambda)=c_{b i}-\varphi_{c_{b i 1}}+\left(\varphi_{c_{b i 1}}-\varphi_{c_{b i 2}}\right) \lambda ; \tilde{c}_{U b i}(\lambda)=c_{b i}-\varphi_{c_{b i 4}}+\left(\varphi_{c_{b i 4}}-\varphi_{c_{b i 3}}\right) \lambda, \tilde{c}_{L c i}(\lambda)=c_{c i}-\varphi_{c_{c i 1}}+$ $\left(\varphi_{c_{c i 1}}-\varphi_{c_{c i 2}}\right) \lambda ; \tilde{c}_{U c i}(\lambda)=c_{c i}-\varphi_{c_{c i 4}}+\left(\varphi_{c_{c i 4}}-\varphi_{c_{c i 3}}\right) \lambda$, and $\tilde{c}_{L p i}(\lambda)=c_{p i}-\varphi_{c_{p i 1}}+\left(\varphi_{c_{p i 1}}-\varphi_{c_{p i 2}}\right) \lambda ;$ $\tilde{c}_{U p i}(\lambda)=c_{p i}-\varphi_{c_{p i 4}}+\left(\varphi_{c_{p i 4}}-\varphi_{c_{p i 3}}\right) \lambda$. Therefore, by using the signed distance method 4.2,

$$
d_{0}\left(\tilde{P}_{c}\left(m_{i j}, n_{i j}, q_{i j}, k_{i j}, l_{j}\right), \tilde{0}\right)=\frac{1}{2} \int_{0}^{1}\left[\tilde{P}_{c}\left(m_{i j}, n_{i j}, q_{i j}, k_{i j}, l_{j}\right)_{L}(\lambda)+\tilde{P}_{c}\left(m_{i j}, n_{i j}, q_{i j}, k_{i j}, l_{j}\right)_{U}(\lambda)\right] \mathrm{d} \lambda
$$

if $c=1,2$ then $k_{i j}=0$ and if $c=3,4$ then $k_{i j}=n_{i j}-1$,

$$
\begin{aligned}
d_{0}\left(\tilde{S}_{v i}, \tilde{0}\right) & =S_{v i}+\frac{1}{4}\left(\varphi_{S_{v i 4}}+\varphi_{S_{v i 3}}-\varphi_{S_{v i 2}}-\varphi_{S_{v i 1}}\right)>0 \\
d_{0}\left(\tilde{O}_{b i j}, \tilde{0}\right) & =O_{b i j}+\frac{1}{4}\left(\varphi_{O_{b i j 4}}+\varphi_{O_{b i j 3}}-\varphi_{O_{b i j} 2}-\varphi_{O_{b i j 1}}\right)>0 \\
d_{0}\left(\tilde{h}_{m i j}^{f}, \tilde{0}\right) & =h_{m i j}^{f}+\frac{1}{4}\left(\varphi_{h_{m i j 4}^{f}}+\varphi_{h_{m i j 3}^{f}}-\varphi_{h_{m i j 2}^{f}}-\varphi_{h_{m i j 1}^{f}}\right)>0 \\
d_{0}\left(\tilde{h}_{m i j}^{p}, \tilde{0}\right) & =h_{m i j}^{p}+\frac{1}{4}\left(\varphi_{h_{m i j 4}^{p}}+\varphi_{h_{m i j 3}^{p}}-\varphi_{h_{m i j 2}^{p}}-\varphi_{h_{m i j 1}^{p}}\right)>0 \\
d_{0}\left(\tilde{h}_{d i j}^{p}, \tilde{0}\right) & =h_{d i j}^{p}+\frac{1}{4}\left(\varphi_{h_{d i j 4}^{p}}+\varphi_{h_{d i j 3}^{p}}-\varphi_{h_{d i j 2}^{p}}-\varphi_{h_{d i j 1}^{p}}\right)>0 \\
d_{0}\left(\tilde{h}_{r i j}^{p}, \tilde{0}\right) & =h_{r i j}^{p}+\frac{1}{4}\left(\varphi_{h_{r i j 4}^{p}}+\varphi_{h_{r i j 3}^{p}}-\varphi_{h_{r i j 2}^{p}}-\varphi_{h_{r i j 1}^{p}}\right)>0 \\
d_{0}\left(\tilde{c}_{t i j}, \tilde{0}\right) & =c_{t i j}+\frac{1}{4}\left(\varphi_{c_{t i j 4}}+\varphi_{c_{t i j 3}}-\varphi_{c_{t i j 2}}-\varphi_{c_{t i j 1}}\right)>0 \\
d_{0}\left(\tilde{c}_{p r i}, \tilde{0}\right) & =c_{p r i}+\frac{1}{4}\left(\varphi_{c_{p r i 4}}+\varphi_{c_{p r i 3}}-\varphi_{c_{p r i 2}}-\varphi_{c_{p r i 1}}\right)>0 \\
d_{0}\left(\tilde{c}_{b i j}, \tilde{0}\right) & =c_{b i j}+\frac{1}{4}\left(\varphi_{c_{b i j 4}}+\varphi_{c_{b i j 3}}-\varphi_{c_{b i j 2}}-\varphi_{c_{b i j 1}}\right)>0 \\
d_{0}\left(\tilde{c}_{c i j}, \tilde{0}\right) & =c_{c i j}+\frac{1}{4}\left(\varphi_{c_{c i j 4}}+\varphi_{c_{c i j 3}}-\varphi_{c_{c i j 2}}-\varphi_{c_{c i j 1}}\right)>0 \\
d_{0}\left(\tilde{c}_{p i}, \tilde{0}\right) & =c_{p i}+\frac{1}{4}\left(\varphi_{c_{p i 4}}+\varphi_{c_{p i 3}}-\varphi_{c_{p i 2}}-\varphi_{c_{p i 1}}\right)>0 .
\end{aligned}
$$

By inserting (5.1)-(5.11) into the equations (5.12)-(5.15) yields the defuzzified profit function,

For Case 1.

$$
\begin{aligned}
& d_{0}\left(\tilde{P}_{1}\left(m_{i j}, n_{i j}, q_{i j}, l_{j}\right), \tilde{0}\right) \\
& =\sum_{i=1}^{z} \sum_{j=1}^{y} d_{0}\left(\tilde{c}_{b i j}, \tilde{0}\right) d_{i j}+d_{0}\left(\tilde{c}_{c i j}, \tilde{0}\right)\left(d_{i j}+I_{b i j} \frac{n_{i j} q_{i j}}{2 m_{i j}}\right)-\left(\left(\gamma_{i} d_{0}\left(\tilde{c}_{p i}, \tilde{0}\right)+d_{0}\left(\tilde{c}_{p r i}, \tilde{0}\right)\right.\right. \\
& \left.\quad+d_{0}\left(\tilde{c}_{b i j}, \tilde{0}\right)\right) d_{i j}+\left(d_{0}\left(\tilde{S}_{v i}, \tilde{0}\right)+n_{i j} d_{0}\left(\tilde{O}_{b i j}, \tilde{0}\right)+m_{i j} d_{0}\left(\tilde{c}_{t i j}, \tilde{0}\right)+n_{i j} B\left(l_{j}\right)\right) \frac{d_{i j}}{n_{i j} q_{i j}} \\
& \quad+d_{0}\left(\tilde{h}_{m i j}^{f}, \tilde{0}\right)\left(\frac{\left(m_{i j}+1\right) n_{i j} q_{i j}}{2 m_{i j}}-\left(n_{i j}-1\right) \frac{q_{i j} d_{i j}}{2 p_{i}}\right)+\left(d_{0}\left(\tilde{h}_{m i j}^{p}, \tilde{0}\right)+d_{0}\left(\tilde{h}_{m i j}^{f}, \tilde{0}\right)\right) \frac{q_{i j} d_{i j}}{2 p_{i}} \\
& \left.\quad+d_{0}\left(\tilde{h}_{r i j}^{p}, \tilde{0}\right)\left(\frac{n_{i j} q_{i j}}{2}-\left(n_{i j}-1\right) \frac{q_{i j} d_{i j}}{2 p_{i}}\right)+\left(d_{0}\left(\tilde{h}_{d i j}^{p}, \tilde{0}\right)+d_{0}\left(\tilde{h}_{m i j}^{p}, \tilde{0}\right)\right) d_{i j} l_{j}\right)
\end{aligned}
$$

subject to $\left(n_{i j} q_{i j}-\left(n_{i j}-1\right) q_{i j} \frac{d_{i j}}{p_{i}}\right) \leq I_{\max }, q_{i j}>0, m_{i j}, n_{i j}$ and $l_{j}$ are positive integers.

For Case 2.

$$
d_{0}\left(\tilde{P}_{2}\left(m_{i j}, n_{i j}, q_{i j}, l_{j}\right), \tilde{0}\right)
$$




$$
\begin{aligned}
= & \sum_{i=1}^{z} \sum_{j=1}^{y} d_{0}\left(\tilde{c}_{b i j}, \tilde{0}\right)\left(d_{i j}+I_{v i j} \frac{\beta_{i j}\left(1+\alpha_{i j}\right) n_{i j} q_{i j}}{m_{i j}}\right)+d_{0}\left(\tilde{c}_{c i}, \tilde{0}\right)\left(d_{i j}+I_{b i j} \frac{n_{i j} q_{i j}}{2 m_{i j}}\right. \\
& \left.\times\left(2 \alpha_{i j}+1+2 \beta_{i j}\left(1+\alpha_{i j}\right)\right)\right)-\left(\left(\gamma_{i} d_{0}\left(\tilde{c}_{p i}, \tilde{0}\right)+d_{0}\left(\tilde{c}_{p r i}, \tilde{0}\right)+d_{0}\left(\tilde{c}_{b i j}, \tilde{0}\right)\right) d_{i j}+\left(d_{0}\left(\tilde{S}_{v i}, \tilde{0}\right)\right.\right. \\
& \left.+n_{i j} d_{0}\left(\tilde{O}_{b i j}, \tilde{0}\right)+m_{i j} d_{0}\left(\tilde{c}_{t i j}, \tilde{0}\right)+n_{i j} B\left(l_{j}\right)\right) \frac{d_{i j}}{n_{i j} q_{i j}}+d_{0}\left(\tilde{h}_{m i j}^{f}, \tilde{0}\right)\left(\left(m_{i j}+1+2 \alpha_{i j}\right.\right. \\
& \left.\left.+2 \beta_{i j}\left(1+\alpha_{i j}\right)\right) \frac{n_{i j} q_{i j}}{2 m_{i j}}-\left(n_{i j}-1\right) \frac{q_{i j} d_{i j}}{2 p_{i}}\right)+\left(d_{0}\left(\tilde{h}_{m i j}^{p}, \tilde{0}\right)+d_{0}\left(\tilde{h}_{m i j}^{f}, \tilde{0}\right)\right) \frac{q_{i j} d_{i j}}{2 p_{i}} \\
& +d_{0}\left(\tilde{h}_{r i j}^{p}, \tilde{0}\right)\left(\frac{n_{i j} q_{i j}}{2}-\left(n_{i j}-1\right) \frac{q_{i j} d_{i j}}{2 p_{i}}\right)+d_{0}\left(\tilde{c}_{b i j}, \tilde{0}\right) I_{v i j}\left(\frac{\beta_{i j}\left(1+\alpha_{i j}\right) n_{i j} q_{i j}}{m_{i j}}\right) \\
& \left.+\left(d_{0}\left(\tilde{h}_{d i j}^{p}, \tilde{0}\right)+d_{0}\left(\tilde{h}_{m i j}^{p}, \tilde{0}\right)\right) d_{i j} l_{j}\right)
\end{aligned}
$$

subject to $\left(n_{i j} q_{i j}-\left(n_{i j}-1\right) q_{i j} \frac{d_{i j}}{p_{i}}\right) \leq I_{\max }, q_{i j}>0, m_{i j}, n_{i j}$ and $l_{j}$ are positive integers.

For Case 3.

$$
\begin{aligned}
d_{0}\left(\tilde{P}_{3}\left(m_{i j}, n_{i j}, q_{i j}, k_{i j}, l_{j}\right), \tilde{0}\right) \\
=\sum_{i=1}^{z} \sum_{j=1}^{y} d_{0}\left(\tilde{c}_{b i j}, \tilde{0}\right) d_{i j}+d_{0}\left(\tilde{c}_{c i j}, \tilde{0}\right)\left(d_{i j}+I_{b i j} \frac{n_{i j} q_{i j}}{2 m_{i j}}\right)-\left(\left(\gamma_{i} d_{0}\left(\tilde{c}_{p i}, \tilde{0}\right)+d_{0}\left(\tilde{c}_{p r i}, \tilde{0}\right)\right.\right. \\
\left.\quad+d_{0}\left(\tilde{c}_{b i j}, \tilde{0}\right)\right) d_{i j}+\left(d_{0}\left(\tilde{S}_{v i}, \tilde{0}\right)+n_{i j} d_{0}\left(\tilde{O}_{b i j}, \tilde{0}\right)+m_{i j} d_{0}\left(\tilde{c}_{t i j}, \tilde{0}\right)+n_{i j} B\left(l_{j}\right)\right) \frac{d_{i j}}{n_{i j} q_{i j}} \\
\quad+d_{0}\left(\tilde{h}_{m i j}^{f}, \tilde{0}\right)\left(\frac{\left(m_{i j}+1\right) n_{i j} q_{i j}}{2 m_{i j}}-\left(n_{i j}-1\right) \frac{q_{i j} d_{i j}}{2 p_{i}}\right)+\left(d_{0}\left(\tilde{h}_{m i j}^{p}, \tilde{0}\right)+d_{0}\left(\tilde{h}_{m i j}^{f}, \tilde{0}\right)\right) \\
\quad \times \frac{q_{i j} d_{i j}}{2 p_{i}}+\left(d_{0}\left(\tilde{h}_{m i j}^{p}, \tilde{0}\right)-d_{0}\left(\tilde{h}_{r i j}^{p}, \tilde{0}\right)\right)\left(\frac{q_{i j}\left(p_{i}-d_{i j}\right)}{2 p_{i}}\right)\left(n_{i j}-1\right)+d_{0}\left(\tilde{h}_{r i j}^{p}, \tilde{0}\right) \\
\left.\quad \times\left(\frac{n_{i j} q_{i j}}{2}-\left(n_{i j}-1\right) \frac{q_{i j} d_{i j}}{2 p_{i}}\right)+\left(d_{0}\left(\tilde{h}_{d i j}^{p}, \tilde{0}\right)+d_{0}\left(\tilde{h}_{m i j}^{p}, \tilde{0}\right)\right) d_{i j} l_{j}\right)
\end{aligned}
$$

subject to $\left(\left(n_{i j}-k_{i j}\right) q_{i j}-\left(n_{i j}-k_{i j}-1\right) q_{i j} \frac{d_{i j}}{p_{i}}\right) \leq I_{\max }, q_{i j}>0, k_{i j} \leq n_{i j}-1, m_{i j}, n_{i j}$ and $\mathrm{l}_{j}$ are positive integers.

For Case 4.

$$
\begin{aligned}
d_{0}\left(\tilde{P}_{4}\left(m_{i j}, n_{i j}, q_{i j}, k_{i j}, l_{j}\right), \tilde{0}\right) \\
=\sum_{i=1}^{z} \sum_{j=1}^{y} d_{0}\left(\tilde{c}_{b i j}, \tilde{0}\right)\left(d_{i j}+I_{v i j} \frac{\beta_{i j}\left(1+\alpha_{i j}\right) n_{i j} q_{i j}}{m_{i j}}\right)+d_{0}\left(\tilde{c}_{c i j}, \tilde{0}\right)\left(d_{i j}+I_{b i j} \frac{n_{i j} q_{i j}}{2 m_{i j}}\right. \\
\left.\quad \times\left(2 \alpha_{i j}+1+2 \beta_{i j}\left(1+\alpha_{i j}\right)\right)\right)-\left(\left(\gamma_{i} d_{0}\left(\tilde{c}_{p i}, \tilde{0}\right)+d_{0}\left(\tilde{c}_{p r i}, \tilde{0}\right)+d_{0}\left(\tilde{c}_{b i j}, \tilde{0}\right)\right) d_{i j}\right. \\
\quad+\left(d_{0}\left(\tilde{S}_{v i}, \tilde{0}\right)+n_{i j} d_{0}\left(\tilde{O}_{b i j}, \tilde{0}\right)+m_{i j} d_{0}\left(\tilde{c}_{t i j}, \tilde{0}\right)+n_{i j} B\left(l_{j}\right)\right) \frac{d_{i j}}{n_{i j} q_{i j}}+d_{0}\left(\tilde{h}_{m i j}^{f}, \tilde{0}\right) \\
\quad \times\left(\frac{\left(m_{i j}+1+2 \alpha_{i j}+2 \beta_{i j}\left(1+\alpha_{i j}\right)\right) n_{i j} q_{i j}}{2 m_{i j}}-\left(n_{i j}-1\right) \frac{q_{i j} d_{i j}}{2 p_{i}}\right)+\left(d_{0}\left(\tilde{h}_{m i j}^{p}, \tilde{0}\right)\right. \\
\left.\quad+d_{0}\left(\tilde{h}_{m i j}^{f}, \tilde{0}\right)\right) \frac{q_{i j} d_{i j}}{2 p_{i}}+d_{0}\left(\tilde{h}_{r i j}^{p}, \tilde{0}\right)\left(\frac{n_{i j} q_{i j}}{2}-\left(n_{i j}-1\right) \frac{q_{i j} d_{i j}}{2 p_{i}}\right)+d_{0}\left(\tilde{c}_{b i j}, \tilde{0}\right) I_{v i j}
\end{aligned}
$$




$$
\begin{aligned}
& \times\left(\frac{\beta_{i j}\left(1+\alpha_{i j}\right) n_{i j} q_{i j}}{m_{i j}}\right)+\left(d_{0}\left(\tilde{h}_{m i j}^{p}, \tilde{0}\right)-d_{0}\left(\tilde{h}_{r i j}^{p}, \tilde{0}\right)\right)\left(\frac{q_{i j}\left(p_{i}-d_{i j}\right)}{2 p_{i}}\right)\left(n_{i j}-1\right) \\
& \left.+\left(d_{0}\left(\tilde{h}_{d i j}^{p}, \tilde{0}\right)+d_{0}\left(\tilde{h}_{m i j}^{p}, \tilde{0}\right)\right) d_{i j} l_{j}\right)
\end{aligned}
$$

subject to $\left(\left(n_{i j}-k_{i j}\right) q_{i j}-\left(n_{i j}-k_{i j}-1\right) q_{i j} \frac{d_{i j}}{p_{i}}\right) \leq I_{\max }, q_{i j}>0, k_{i j} \leq n_{i j}-1, m_{i j}, n_{i j}$ and $l_{j}$ are positive integers.

\section{Solution PROCEDURE}

In this section, we derive the optimal value of $q_{i j}$ and demonstrate the concavity of the integrated profit function with respect to the decision variable $q_{i j}$. In this model, the number of shipment $n_{i j}$, the number of payment $m_{i j}$ and the number of delayed deliveries $k_{i j}$ are assumed to be positive integer variables. The given integrated profit function (5.12)-(5.15) seems to be non-linear. To solve this non-linear programming problem, we have focused on some property to obtain the optimal solutions.

Property 6.1. For given values of $m_{i j}, n_{i j}$ and $l_{j} \in\left[l_{j, f}, l_{j, f-1}\right], d_{0}\left(\tilde{P}_{c}, \tilde{0}\right)$ is concave in $q_{i j}$.

Proof. On taking the first and second order partial derivatives of (5.12)-(5.15) with respect to $q_{i j}$, we obtain For Case 1.

$$
\begin{aligned}
\frac{\partial d_{0}\left(\tilde{P}_{1}\left(q_{i j} \mid m_{i j}^{*}, n_{i j}^{*}, l_{j}^{*}\right), \tilde{0}\right)}{\partial q_{i j}} & \frac{B\left(l_{j}\right) d_{i j}}{q_{i j}^{2}}-\frac{d_{i j}}{2 p_{i}}\left(d_{0}\left(\tilde{h}_{m i j}^{f}, \tilde{0}\right)+d_{0}\left(\tilde{h}_{m i j}^{p}, \tilde{0}\right)-d_{0}\left(\tilde{h}_{m i j}^{f}, \tilde{0}\right)\left(n_{i j}-1\right)\right) \\
& -d_{0}\left(\tilde{h}_{r i j}^{p}, \tilde{0}\right)\left(\frac{n_{i j}}{2}-\frac{d_{i j}\left(n_{i j}-1\right)}{2 p_{i}}\right)+\frac{d_{i j}}{q_{i j}^{2}} d_{0}\left(\tilde{O}_{b i j}, \tilde{0}\right)+\frac{n_{i j} I_{b i j}}{2 m_{i j}} d_{0}\left(\tilde{c}_{c i j}, \tilde{0}\right) \\
& +\frac{d_{i j}}{n_{i j} q_{i j}^{2}} d_{0}\left(\tilde{S}_{v i}, \tilde{0}\right)-\frac{n_{i j}\left(m_{i j}+1\right)}{2 m_{i j}} d_{0}\left(\tilde{h}_{m i j}^{f}, \tilde{0}\right)+\frac{m_{i j} d_{i j}}{n_{i j} q_{i j}^{2}} d_{0}\left(\tilde{c}_{t i j}, \tilde{0}\right)
\end{aligned}
$$

and

$$
\frac{\partial^{2} d_{0}\left(\tilde{P}_{1}\left(q_{i j} \mid m_{i j}^{*}, n_{i j}^{*}, l_{j}^{*}\right), \tilde{0}\right)}{\partial q_{i j}^{2}}=-\frac{2 d_{i j} B\left(l_{j}\right)}{q_{i j}^{3}}-\frac{2 d_{i j}}{q_{i j}^{3}} d_{0}\left(\tilde{O}_{b i j}, \tilde{0}\right)-\frac{2 d_{i j}}{n_{i j} q_{i j}^{3}} d_{0}\left(\tilde{S}_{v i}, \tilde{0}\right)-\frac{2 m_{i j} d_{i j}}{n_{i j} q_{i j}^{3}} d_{0}\left(\tilde{c}_{t i j}, \tilde{0}\right)<0 .
$$

For Case 2.

$$
\begin{aligned}
\frac{\partial d_{0}\left(\tilde{P}_{2}\left(q_{i j} \mid m_{i j}^{*}, n_{i j}^{*}, l_{j}^{*}\right), \tilde{0}\right)}{\partial q_{i j}}= & \frac{B\left(l_{j}\right) d_{i j}}{q_{i j}^{2}}-\frac{d_{i j}}{2 p_{i}}\left(d_{0}\left(\tilde{h}_{m i j}^{f}, \tilde{0}\right)+d_{0}\left(\tilde{h}_{m i j}^{p}, \tilde{0}\right)-d_{0}\left(\tilde{h}_{m i j}^{f}, \tilde{0}\right)\left(n_{i j}-1\right)\right) \\
& -d_{0}\left(\tilde{h}_{r i j}^{p}, \tilde{0}\right)\left(\frac{n_{i j}}{2}-\frac{d_{i j}\left(n_{i j}-1\right)}{2 p_{i}}\right)+\frac{d_{i j}}{q_{i j}^{2}} d_{0}\left(\tilde{O}_{b i j}, \tilde{0}\right)+\frac{n_{i j} I_{b i j}}{2 m_{i j}} d_{0}\left(\tilde{c}_{c i j}, \tilde{0}\right) \\
& \times\left(2 \alpha_{i j}+2 \beta_{i j}\left(\alpha_{i j}+1\right)+1\right)+\frac{d_{i j}}{n_{i j} q_{i j}^{2}} d_{0}\left(\tilde{S}_{v i}, \tilde{0}\right)-\frac{n_{i j}}{2 m_{i j}} d_{0}\left(\tilde{h}_{m i j}^{f}, \tilde{0}\right) \\
& \times\left(2 \alpha_{i j}+m_{i j}+2 \beta_{i j}\left(\alpha_{i j}+1\right)+1\right)+\frac{m_{i j} d_{i j}}{n_{i j} q_{i j}^{2}} d_{0}\left(\tilde{c}_{t i j}, \tilde{0}\right)
\end{aligned}
$$


and

$$
\frac{\partial^{2} d_{0}\left(\tilde{P}_{2}\left(q_{i j} \mid m_{i j}^{*}, n_{i j}^{*}, l_{j}^{*}\right), \tilde{0}\right)}{\partial q_{i j}^{2}}=-\frac{2 d_{i j} B\left(l_{j}\right)}{q_{i j}^{3}}-\frac{2 d_{i j}}{q_{i j}^{3}} d_{0}\left(\tilde{O}_{b i j}, \tilde{0}\right)-\frac{2 d_{i j}}{n_{i j} q_{i j}^{3}} d_{0}\left(\tilde{S}_{v i}, \tilde{0}\right)-\frac{2 m_{i j} d_{i j}}{n_{i j} q_{i j}^{3}} d_{0}\left(\tilde{c}_{t i j}, \tilde{0}\right)<0 .
$$

For Case 3.

$$
\begin{aligned}
\frac{\partial d_{0}\left(\tilde{P}_{3}\left(q_{i j} \mid m_{i j}^{*}, n_{i j}^{*}, k_{i j}^{*}, l_{j}^{*}\right), \tilde{0}\right)}{\partial q_{i j}}= & \frac{B\left(l_{j}\right) d_{i j}}{q_{i j}^{2}}-\frac{d_{i j}}{2 p_{i}}\left(d_{0}\left(\tilde{h}_{m i j}^{f}, \tilde{0}\right)+d_{0}\left(\tilde{h}_{m i j}^{p}, \tilde{0}\right)-d_{0}\left(\tilde{h}_{m i j}^{f}, \tilde{0}\right)\left(n_{i j}-1\right)\right) \\
& -d_{0}\left(\tilde{h}_{r i j}^{p}, \tilde{0}\right)\left(\frac{n_{i j}}{2}-\frac{d_{i j}\left(n_{i j}-1\right)}{2 p_{i}}\right)+\frac{d_{i j}}{q_{i j}^{2}} d_{0}\left(\tilde{O}_{b i j}, \tilde{0}\right)+\frac{n_{i j} I_{b i j}}{2 m_{i j}} d_{0}\left(\tilde{c}_{c i j}, \tilde{0}\right) \\
& +\frac{d_{i j}}{n_{i j} q_{i j}^{2}} d_{0}\left(\tilde{S}_{v i}, \tilde{0}\right)-\frac{n_{i j}\left(m_{i j}+1\right)}{2 m_{i j}} d_{0}\left(\tilde{h}_{m i j}^{f}, \tilde{0}\right)+\frac{m_{i j} d_{i j}}{n_{i j} q_{i j}^{2}} d_{0}\left(\tilde{c}_{t i j}, \tilde{0}\right) \\
& +\frac{\left(d_{i j}-p_{i}\right)\left(n_{i j}-1\right)}{2 p_{i}}\left(d_{0}\left(\tilde{h}_{m i j}^{f}, \tilde{0}\right)-d_{0}\left(\tilde{h}_{r i j}^{p}, \tilde{0}\right)\right)
\end{aligned}
$$

and

$$
\begin{aligned}
\frac{\partial^{2} d_{0}\left(\tilde{P}_{3}\left(q_{i j} \mid m_{i j}^{*}, n_{i j}^{*}, k_{i j}^{*}, l_{j}^{*}\right), \tilde{0}\right)}{\partial q_{i j}^{2}}= & -\frac{2 d_{i j} B\left(l_{j}\right)}{q_{i j}^{3}}-\frac{2 d_{i j}}{q_{i j}^{3}} d_{0}\left(\tilde{O}_{b i j}, \tilde{0}\right)-\frac{2 d_{i j}}{n_{i j} q_{i j}^{3}} d_{0}\left(\tilde{S}_{v i}, \tilde{0}\right) \\
& -\frac{2 m_{i j} d_{i j}}{n_{i j} q_{i j}^{3}} d_{0}\left(\tilde{c}_{t i j}, \tilde{0}\right)<0 .
\end{aligned}
$$

For Case 4.

$$
\begin{aligned}
\frac{\partial d_{0}\left(\tilde{P}_{4}\left(q_{i j} \mid m_{i j}^{*}, n_{i j}^{*}, k_{i j}^{*}, l_{j}^{*}\right), \tilde{0}\right)}{\partial q_{i j}}= & \frac{B\left(l_{j}\right) d_{i j}}{q_{i j}^{2}}-\frac{d_{i j}}{2 p_{i}}\left(d_{0}\left(\tilde{h}_{m i j}^{f}, \tilde{0}\right)+d_{0}\left(\tilde{h}_{m i j}^{p}, \tilde{0}\right)-d_{0}\left(\tilde{h}_{m i j}^{f}, \tilde{0}\right)\left(n_{i j}-1\right)\right) \\
& -d_{0}\left(\tilde{h}_{r i j}^{p}, \tilde{0}\right)\left(\frac{n_{i j}}{2}-\frac{d_{i j}\left(n_{i j}-1\right)}{2 p_{i}}\right)+\frac{d_{i j}}{q_{i j}^{2}} d_{0}\left(\tilde{O}_{b i j}, \tilde{0}\right)+\frac{n_{i j} I_{b i j}}{2 m_{i j}} \\
& \times\left(2 \alpha_{i j}+2 \beta_{i j}\left(\alpha_{i j}+1\right)+1\right) d_{0}\left(\tilde{c}_{c i j}, \tilde{0}\right)+\frac{d_{i j}}{n_{i j} q_{i j}^{2}} d_{0}\left(\tilde{S}_{v i}, \tilde{0}\right) \\
& -\frac{n_{i j}\left(2 \alpha_{i j}+m_{i j}+2 \beta_{i j}\left(\alpha_{i j}+1\right)+1\right)}{2 m_{i j}} d_{0}\left(\tilde{h}_{m i j}^{f}, \tilde{0}\right)+\frac{m_{i j} d_{i j}}{n_{i j} q_{i j}^{2}} d_{0}\left(\tilde{c}_{t i j}, \tilde{0}\right) \\
& +\frac{\left(d_{i j}-p_{i}\right)\left(n_{i j}-1\right)}{2 p_{i}}\left(d_{0}\left(\tilde{h}_{m i j}^{f}, \tilde{0}\right)-d_{0}\left(\tilde{h}_{r i j}^{p}, \tilde{0}\right)\right)
\end{aligned}
$$

and

$$
\begin{aligned}
\frac{\partial^{2} d_{0}\left(\tilde{P}_{4}\left(q_{i j} \mid m_{i j}^{*}, n_{i j}^{*}, k_{i j}^{*}, l_{j}^{*}\right), \tilde{0}\right)}{\partial q_{i j}^{2}}= & -\frac{2 d_{i j} B\left(l_{j}\right)}{q_{i j}^{3}}-\frac{2 d_{i j}}{q_{i j}^{3}} d_{0}\left(\tilde{O}_{b i j}, \tilde{0}\right) \\
& -\frac{2 d_{i j}}{n_{i j} q_{i j}^{3}} d_{0}\left(\tilde{S}_{v i}, \tilde{0}\right)-\frac{2 m_{i j} d_{i j}}{n_{i j} q_{i j}^{3}} d_{0}\left(\tilde{c}_{t i j}, \tilde{0}\right)<0 .
\end{aligned}
$$

Therefore, for fixed $m_{i j}, n_{i j}$ and $l_{j} \in\left[l_{j, f}, l_{j, f-1}\right], d_{0}\left(\tilde{P}_{c}, \tilde{0}\right)$ is concave in $q_{i j}$. Hence, this completes the proof of Property 6.1. 
Result. From the Property 6.1,

For Case 1. We obtain the optimal value of $q_{i j}(6.9)$ by equating $(6.1)$ to zero, which maximize the $d_{0}\left(\tilde{P}_{1}, \tilde{0}\right)$.

$$
q_{i j}=\sqrt{\frac{2 m_{i j} d_{i j} p_{i}\left(d_{0}\left(\tilde{S}_{v i}, \tilde{0}\right)+n_{i j} B\left(l_{j}\right)+n_{i j} d_{0}\left(\tilde{O}_{b i j}, \tilde{0}\right)+m_{i j} d_{0}\left(\tilde{c}_{t i j}, \tilde{0}\right)\right)}{n_{i j}\left(d_{0}\left(\tilde{h}_{r i j}^{p}, \tilde{0}\right)\left(m_{i j} d_{i j}-m_{i j} n_{i j} d_{i j}+m_{i j} n_{i j} p_{i}\right)+\kappa_{1}+\Gamma_{1}\right)}}
$$

where $\kappa_{1}=d_{0}\left(\tilde{h}_{m i j}^{f}, \tilde{0}\right)\left(2 m_{i j} d_{i j}+n_{i j} p_{i}-m_{i j} n_{i j} d_{i j}+m_{i j} n_{i j} p_{i}\right) \quad$ and $\quad \Gamma_{1}=m_{i j} d_{i j} d_{0}\left(\tilde{h}_{m i j}^{p}, \tilde{0}\right)-$ $n_{i j} I_{b i j} p_{i} d_{0}\left(\tilde{c}_{c i j}, \tilde{0}\right)$.

For Case 2. We obtain the optimal value of $q_{i j}$ in (6.10) by equating (6.3) to zero, which maximize the $d_{0}\left(\tilde{P}_{2}, \tilde{0}\right)$.

$$
q_{i j}=\sqrt{\frac{2 m_{i j} d_{i j} p_{i}\left(d_{0}\left(\tilde{S}_{v i}, \tilde{0}\right)+n_{i j} B\left(l_{j}\right)+n_{i j} d_{0}\left(\tilde{O}_{b i j}, \tilde{0}\right)+m_{i j} d_{0}\left(\tilde{c}_{t i j}, \tilde{0}\right)\right)}{n_{i j}\left(d_{0}\left(\tilde{h}_{r i j}^{p}, \tilde{0}\right)\left(m_{i j} d_{i j}-m_{i j} n_{i j} d_{i j}+m_{i j} n_{i j} p_{i}\right)+\kappa_{2}+\Gamma_{2}\right)}}
$$

where $\kappa_{2}=d_{0}\left(\tilde{h}_{m i j}^{f}, \tilde{0}\right)\left(2 d_{i j} m_{i j}-d_{i j} m_{i j} n_{i j}+2 p_{i} \alpha_{i j} n_{i j}+2 p_{i} \beta_{i j} n_{i j}+p_{i} m_{i j} n_{i j}+2 p_{i} \alpha_{i j} \beta_{i j} n_{i j}\right) \quad$ and $\Gamma_{2}=m_{i j} d_{i j} d_{0}\left(\tilde{h}_{m i j}^{p}, \tilde{0}\right)-I_{b i j} p_{i} n_{i j} d_{0}\left(\tilde{c}_{c i j}, 0\right)\left(1+2 \alpha_{i j}+2 \beta_{i j}+2 \alpha_{i j} \beta_{i j}\right)$.

For Case 3. We obtain the optimal value of $q_{i j}$ in (6.11) by equating (6.5) to zero, which maximize the $d_{0}\left(\tilde{P}_{3}, \tilde{0}\right)$.

$$
q_{i j}=\sqrt{\frac{2 m_{i j} d_{i j} p_{i}\left(d_{0}\left(\tilde{S}_{v i}, \tilde{0}\right)+n_{i j} B\left(l_{j}\right)+n_{i j} d_{0}\left(\tilde{O}_{b i j}, \tilde{0}\right)+m_{i j} d_{0}\left(\tilde{c}_{t i j}, \tilde{0}\right)\right)}{n_{i j}\left(d_{0}\left(\tilde{h}_{r i j}^{p}, \tilde{0}\right)\left(m_{i j} p_{i}\right)+d_{0}\left(\tilde{h}_{m i j}^{f}, \tilde{0}\right)\left(2 m_{i j} d_{i j}+n_{i j} p_{i}-m_{i j} n_{i j} d_{i j}+m_{i j} n_{i j} p_{i}\right)+\Gamma_{3}\right)}}
$$

where $\Gamma_{3}=\left(2 d_{i j} m_{i j}-p_{i} m_{i j}-d_{i j} m_{i j} n_{i j}+p_{i} m_{i j} n_{i j}\right) d_{0}\left(\tilde{h}_{m i j}^{p}, \tilde{0}\right)-I_{b i j} p_{i} n_{i j} d_{0}\left(\tilde{c}_{c i j}, \tilde{0}\right)$.

For Case 4. We obtain the optimal value of $q_{i j}$ in (6.12) by equating (6.7) to zero, which maximize the $d_{0}\left(\tilde{P}_{4}, \tilde{0}\right)$.

$$
q_{i j}=\sqrt{\frac{2 m_{i j} d_{i j} p_{i}\left(d_{0}\left(\tilde{S}_{v i}, \tilde{0}\right)+n_{i j} B\left(l_{j}\right)+n_{i j} d_{0}\left(\tilde{O}_{b i j}, \tilde{0}\right)+m_{i j} d_{0}\left(\tilde{c}_{t i j}, \tilde{0}\right)\right)}{n_{i j}\left(d_{0}\left(\tilde{h}_{r i j}^{p}, \tilde{0}\right)\left(m_{i j} p_{i}\right)+d_{0}\left(\tilde{h}_{m i j}^{f}, \tilde{0}\right)\left(2 d_{i j}+p_{i} n_{i j}-d_{i j} m_{i j} n_{i j}+\kappa_{4}\right)+\Gamma_{4}\right)}}
$$

where $\kappa_{4}=2 p_{i} \alpha_{i j} n_{i j}+2 p_{i} \beta_{i j} n_{i j}+p_{i} m_{i j} n_{i j}+2 p_{i} \alpha_{i j} \beta_{i j} n_{i j}$ and $\Gamma_{4}=\left(2 d_{i j} m_{i j}-p_{i} m_{i j}-d_{i j} m_{i j} n_{i j}+\right.$ $\left.p_{i} m_{i j} n_{i j}\right) d_{0}\left(\tilde{h}_{m i j}^{p}, \tilde{0}\right)-I_{b i j} p_{i} n_{i j}\left(1+2 \alpha_{i j} n_{i j}+2 \beta_{i j}+2 \alpha_{i j} \beta_{i j}\right) d_{0}\left(\tilde{c}_{c i j}, \tilde{0}\right)$.

Property 6.2. For fixed values of $m_{i j}, n_{i j}$ and $q_{i j}$, the integrated profit function $d_{0}\left(\tilde{P}_{c}\left(l_{j}\right), \tilde{0}\right)$, where $c=$ $1,2,3,4$ is linear on $l_{j}$.

Proof. On taking the first order derivatives of profit functions (5.12)-(5.15) will lead to

$$
\begin{aligned}
\frac{\partial d_{0}\left(\tilde{P}_{c}\left(l_{j}\right), \tilde{0}\right)}{\partial l_{j}}= & d_{i j}\left[\frac{e_{j}}{q_{i j}}-\left(h_{d i j}^{p}+\frac{1}{4}\left(\varphi_{h_{d i j 4}^{p}}+\varphi_{h_{d i j 3}^{p}}-\varphi_{h_{d i j 2}^{p}}-\varphi_{h_{d i j 1}^{p}}\right)+h_{m i j}^{f}\right.\right. \\
& \left.\left.+\frac{1}{4}\left(\varphi_{h_{m i j 4}^{f}}+\varphi_{h_{m i j 3}^{f}}-\varphi_{h_{m i j 2}^{f}}-\varphi_{h_{m i j 1}^{f}}\right)\right)\right]
\end{aligned}
$$


TABLE 2. Input parameter for trapezoidal fuzzy number.

\begin{tabular}{|c|c|c|c|c|c|c|c|c|c|c|c|}
\hline \multirow{2}{*}{$\begin{array}{l}\text { Fuzzy } \\
\text { parameters of } \\
S_{v i}\end{array}$} & \multicolumn{3}{|c|}{ Item $i$} & \multirow{2}{*}{$\begin{array}{l}\text { Fuzzy } \\
\text { parameters of } \\
c_{\text {pri }}\end{array}$} & \multicolumn{3}{|c|}{ Item $i$} & \multirow{2}{*}{$\begin{array}{l}\text { Fuzzy } \\
\text { parameters of } \\
c_{p i}\end{array}$} & \multicolumn{3}{|c|}{ Item $i$} \\
\hline & 1 & 2 & 3 & & 1 & 2 & 3 & & 1 & 2 & 3 \\
\hline$\varphi_{S_{v i 1}}$ & 300 & 300 & 300 & $\varphi_{c_{p r i 1}}$ & 0.7 & 0.7 & 0.7 & $\varphi_{c_{p i 1}}$ & 2.6 & 2.3 & 2 \\
\hline$\varphi_{S_{v i 2}}$ & 200 & 200 & 200 & $\varphi_{c_{\text {pri2 }}}$ & 0.4 & 0.4 & 0.4 & $\varphi_{c_{p i 2}}$ & 1.6 & 1.3 & 1 \\
\hline$\varphi_{S_{v i 3}}$ & 150 & 150 & 150 & $\varphi_{c_{p r i 3}}$ & 0.4 & 0.4 & 0.4 & $\varphi_{c_{p i 3}}$ & 2 & 1.8 & 1.5 \\
\hline$\varphi_{S_{v i 4}}$ & 250 & 250 & 250 & $\varphi_{c_{\text {pri4 }}}$ & 0.9 & 0.9 & 0.9 & $\varphi_{c_{p i 4}}$ & 2.5 & 2.3 & 2.2 \\
\hline
\end{tabular}

where $c=1,2,3,4$. Equation (6.13) result as a constant. If $\frac{e_{j}}{q_{i j}}>\left[d_{0}\left(\tilde{h}_{d i j}^{p}, \tilde{0}\right)+d_{0}\left(\tilde{h}_{m i j}^{f}, \tilde{0}\right)\right]$, then the $d_{0}\left(\tilde{P}_{c}\left(l_{j}\right), \tilde{0}\right)$ is linear increase on $l_{j}$. If $\frac{e_{j}}{q_{i j}}<\left[d_{0}\left(\tilde{h}_{d i j}^{p}, \tilde{0}\right)+d_{0}\left(\tilde{h}_{m i j}^{f}, \tilde{0}\right)\right]$, then the $d_{0}\left(\tilde{P}_{c}\left(l_{j}\right), \tilde{0}\right)$ is linear decrease on $l_{j}$. If $\frac{e_{j}}{q_{i j}}=\left[d_{0}\left(\tilde{h}_{d i j}^{p}, \tilde{0}\right)+d_{0}\left(\tilde{h}_{m i j}^{f}, \tilde{0}\right)\right]$, then the $d_{0}\left(\tilde{P}_{c}\left(l_{j}\right), \tilde{0}\right)$ is flat on $l_{j}$. Therefore, under each case, the profit function $d_{0}\left(\tilde{P}_{c}\left(l_{j}\right), \tilde{0}\right)$ is linear on $l_{j}$. Hence, this completes the proof of Property 6.2.

For the fixed values of $m_{i j}, n_{i j}$, and $q_{i j}$, the maximum $d_{0}\left(\tilde{P}_{c}\left(l_{j}\right), \tilde{0}\right)$ always occurs only at the end points of $\left[l_{j, f}, l_{j, f-1}\right]$.

\section{NumericAl ANALYSiS}

Let us consider a two-tier supply chain model for three items and three consignees, that is $z=3, y=3$. For simplicity the parameters for three items and three consignee are arranged in the row matrix, i.e., production rate $p_{i}=\left[p_{1}, p_{2}, p_{3}\right]$ is the production rate of $i$ th item, demand $d_{i j}=\left[d_{11}, d_{12}, d_{13} ; d_{21}, d_{22}, d_{23} ; d_{31}, d_{32}, d_{33}\right]$ is the demand of the $i$ th item for $j$ th consignee.

The numerical data was taken from Zavanella and Zanoni [40], Sarker [37], Sarkar et al. [27] and Zahran et al. [39].

Example 7.1. For Case 1. $\left(h_{m i j}^{p}>h_{\text {rij }}^{p}\right)$. Parameters related to Consignor: $S_{v i}=[400,370,345](\$ /$ setup $)$, $c_{\text {pri }}=[3,2.5,1](\$ /$ unit $), h_{m i j}^{p}=[15,14.5,16 ; 14.8,16.7,15.9 ; 15,15.7,16](\$ /$ unit $/$ year $), h_{m i j}^{f}=[0.54,0.54$, $0.54 ; 0.51,0.51,0.51 ; 0.48,0.48,0.48]$ (\$/unit/year), $c_{b i j}=[5.4,5.4,5.4 ; 5.4,5.4,5.4 ; 5.4,5.4,5.4](\$ /$ unit $)$, $c_{p i}=[3,2.8,2.4](\$ /$ unit $)$. Parameters related to Consignee: $O_{b i j}=[29,26,25 ; 27,26.5,25.5 ; 26,29$, 26] $(\$ /$ order $), h_{r i j}^{p}=[7,6.8,7 ; 8,7,8 ; 8.5,7,7.8](\$ /$ unit/year $), I_{b i j}=[0.1,0.1,0.1 ; 0.1,0.1,0.1 ; 0.1,0.1$, $0.1](\$ /$ year $), c_{c i j}=[13.9,14,12.29 ; 13.9,14,12.29 ; 13.9,14,12.29](\$ /$ unit $), c_{t i j}=[0.7,0.6,0.75 ; 0.7,0.5$, $0.6 ; 0.65,0.75,0.66]$ (\$/transaction). General parameters: $d_{i j}=[900,600,650 ; 600,650,700 ; 350,400$, 430] (units/year), $p_{i}=[3200,2000,2500]$ (units/year), $h_{d i j}^{p}=[7,7.8,6.2 ; 8.8,7.5,6.8 ; 6.4,6.8,7]$ $(\$ /$ unit/year $), \gamma_{i}=[1,1,1]$. The fuzzy parameteric values are listed out in the Tables 2 and 3 . In addition, the lead time has three components with data shown in Table 4 as well as the summarized lead time components information is given in Table 5. The optimal solution, $l_{j}=[0.0767,0.0767,0.0959]$, $B\left(l_{j}\right)=[18.2000,16.1000,40.6000], m_{i j}=[1,1,1], n_{i j}=[3,3,3]$, the order quantity of three items for first consignee, $\left[q_{11}, q_{21}, q_{31}\right]=[128.84105,96.193021,68.123938]$, for second consignee, $\left[q_{12}, q_{22}, q_{32}\right]=$ $[104.70503,102.54538,80.836474]$, for third consignee, $\left[q_{13}, q_{23}, q_{33}\right]=[111.80159,106.69594,82.509551]$, profit of first consignee on three items, $\left[P_{1}^{11}, P_{1}^{21}, P_{1}^{31}\right]=[3637.5498,2382.1809,1706.8041]$, for second consignee, $\left[P_{1}^{12}, P_{1}^{22}, P_{1}^{32}\right]=[2172.4448,2847.7495,2207.3677]$, for third consignee, $\left[P_{1}^{13}, P_{1}^{23}, P_{1}^{33}\right]=$ $[1044.9304,1678.4404,1419.3938]$, the profit of three consignee is $[7726.5348,7227.5621,4142.7646]$, the overall profit of the supply chain is 19096.861 . 
TABLE 3. Input parameter for trapezoidal fuzzy number.

\begin{tabular}{|c|c|c|c|c|c|c|c|c|c|c|c|c|c|c|c|c|c|}
\hline \multirow{2}{*}{$\begin{array}{l}\text { Fuzzy } \\
\text { parameter }\end{array}$} & \multirow[b]{2}{*}{$g$} & \multirow[b]{2}{*}{$j$} & \multicolumn{3}{|c|}{$i$} & \multirow[b]{2}{*}{$g$} & \multicolumn{3}{|c|}{$i$} & \multirow[b]{2}{*}{$g$} & \multicolumn{3}{|c|}{$i$} & \multirow[b]{2}{*}{$g$} & \multicolumn{3}{|c|}{$i$} \\
\hline & & & 1 & 2 & 3 & & 1 & 2 & 3 & & 1 & 2 & 3 & & 1 & 2 & 3 \\
\hline \multirow{3}{*}{$\varphi_{O_{b i j g}}$} & \multirow{3}{*}{1} & 1 & 25 & 24 & 22 & \multirow{3}{*}{2} & 12 & 18 & 16 & \multirow{3}{*}{3} & 20 & 17 & 11 & \multirow{3}{*}{4} & 24 & 21 & 18 \\
\hline & & 2 & 26 & 22 & 20 & & 24 & 18 & 14 & & 17 & 16 & 10 & & 25 & 19 & 15 \\
\hline & & 3 & 21 & 17 & 23 & & 17 & 15 & 18 & & 15 & 18 & 14 & & 19 & 24 & 22 \\
\hline \multirow{3}{*}{$\varphi_{c_{c i j g}}$} & \multirow{3}{*}{1} & 1 & 6 & 6 & 6 & \multirow{3}{*}{2} & 4 & 4 & 4 & \multirow{3}{*}{3} & 3 & 3 & 3 & \multirow{3}{*}{4} & 5 & 5 & 5 \\
\hline & & 2 & 6 & 6 & 6 & & 4 & 4 & 4 & & 3 & 3 & 3 & & 5 & 5 & 5 \\
\hline & & 3 & 6 & 6 & 6 & & 4 & 4 & 4 & & 3 & 3 & 3 & & 5 & 5 & 5 \\
\hline \multirow{3}{*}{$\varphi_{c_{b i j g}}$} & \multirow{3}{*}{1} & 1 & 5 & 5 & 5 & \multirow{3}{*}{2} & 3 & 3 & 3 & \multirow{3}{*}{3} & 1.5 & 1.5 & 1.5 & \multirow{3}{*}{4} & 3 & 3 & 3 \\
\hline & & 2 & 4.8 & 4.8 & 4.8 & & 4 & 4 & 4 & & 1.2 & 1.2 & 1.2 & & 2 & 2 & 2 \\
\hline & & 3 & 3.8 & 3.8 & 3.8 & & 2 & 2 & 2 & & 0.4 & 0.4 & 0.4 & & 1 & 1 & 1 \\
\hline \multirow{3}{*}{$\varphi_{h_{\text {rijg }}^{p}}^{p}$} & \multirow{3}{*}{1} & 1 & 6 & 6 & 6 & & 3 & 3 & 3 & & 2 & 2 & 2 & & 5 & 5 & 5 \\
\hline & & 2 & 6 & 6 & 6 & 2 & 3 & 3 & 3 & 3 & 2 & 2 & 2 & 4 & 5 & 5 & 5 \\
\hline & & 3 & 6 & 6 & 6 & & 3 & 3 & 3 & & 2 & 2 & 2 & & 5 & 5 & 5 \\
\hline & & 1 & 14 & 14 & 14 & & 10 & 10 & 10 & & 9 & 9 & 9 & & 13 & 13 & 13 \\
\hline$\varphi_{h_{m i j g}^{p}}$ & 1 & 2 & 14 & 14 & 14 & 2 & 10 & 10 & 10 & 3 & 9 & 9 & 9 & 4 & 13 & 13 & 13 \\
\hline & & 3 & 14 & 14 & 14 & & 10 & 10 & 10 & & 9 & 9 & 9 & & 13 & 13 & 13 \\
\hline & & 1 & 6.9 & 6.6 & 6 & & 6 & 5.8 & 4.8 & & 5 & 4 & 6 & & 6 & 5.6 & 6.7 \\
\hline$\varphi_{h_{d i i g}^{p}}$ & 1 & 2 & 7 & 6.5 & 6 & 2 & 4.8 & 3.7 & 5.7 & 3 & 6 & 6.7 & 4 & 4 & 8 & 7 & 5.6 \\
\hline & & 3 & 6 & 6.6 & 6.4 & & 4.4 & 4.7 & 5.4 & & 5.2 & 6 & 5.5 & & 6 & 6.3 & 6.8 \\
\hline & & 1 & 0.45 & 0.40 & 0.35 & & 0.38 & 0.35 & 0.28 & & 0.34 & 0.34 & 0.30 & & 0.48 & 0.44 & 0.40 \\
\hline$\varphi_{h_{m i j i}^{f}}$ & 1 & 2 & 0.48 & 0.35 & 0.25 & 2 & 0.38 & 0.28 & 0.18 & 3 & 0.27 & 0.35 & 0.25 & 4 & 0.30 & 0.40 & 0.35 \\
\hline & & 3 & 0.45 & 0.38 & 0.30 & & 0.38 & 0.28 & 0.26 & & 0.38 & 0.34 & 0.32 & & 0.40 & 0.46 & 0.47 \\
\hline & & 1 & 0.6 & 0.4 & 0.57 & & 0.45 & 0.34 & 0.35 & & 0.35 & 0.25 & 0.34 & & 0.48 & 0.58 & 0.68 \\
\hline$\varphi_{c_{t i j g}}$ & 1 & 2 & 0.65 & 0.43 & 0.58 & 2 & 0.28 & 0.36 & 0.42 & 3 & 0.34 & 0.25 & 0.45 & 4 & 0.68 & 0.43 & 0.57 \\
\hline & & 3 & 0.61 & 0.72 & 0.62 & & 0.31 & 0.45 & 0.45 & & 0.25 & 0.19 & 0.28 & & 0.48 & 0.46 & 0.58 \\
\hline
\end{tabular}

TABLE 4. Lead time components.

\begin{tabular}{lllll}
\hline \hline $\begin{array}{l}\text { Consignee } \\
j\end{array}$ & Lead time components & $\begin{array}{l}\text { Normal duration } \\
n_{j, k}(\text { year })\end{array}$ & $\begin{array}{l}\text { Minimum duration } \\
m_{j, k} \text { (year) }\end{array}$ & $\begin{array}{l}\text { Unit crashing cost } \\
e_{j, k}(\$ / \text { year })\end{array}$ \\
\hline \multirow{3}{*}{1} & $k$ & $20 / 365=0.05479$ & $6 / 365=0.01644$ & $0.1 \times 365=36.5$ \\
& 1 & $20 / 365=0.05479$ & $6 / 365=0.01644$ & $1.2 \times 365=438$ \\
& 2 & $16 / 365=0.04383$ & $9 / 365=0.02465$ & $5.0 \times 365=1825$ \\
\hline \multirow{3}{*}{2} & 3 & $20 / 365=0.05479$ & $6 / 365=0.01644$ & $0.5 \times 365=182.5$ \\
& 1 & $16 / 365=0.04383$ & $9 / 365=0.02465$ & $1.3 \times 365=474.5$ \\
& 2 & $13 / 365=0.035616$ & $6 / 365=0.01644$ & $5.1 \times 365=1861.5$ \\
\hline \multirow{3}{*}{3} & 3 & $25 / 365=0.06849$ & $11 / 365=0.03013$ & $0.4 \times 365=146$ \\
& 1 & $20 / 365=0.05479$ & $6 / 365=0.01644$ & $2.5 \times 365=912.5$ \\
& 2 & $18 / 365=0.04931$ & $11 / 365=0.03013$ & $5.0 \times 365=1825$ \\
\hline
\end{tabular}

Example 7.2. For Case 2. $\left(h_{m i j}^{p}>h_{r i j}^{p}\right)$. Parameters related to Consignor: $I_{v i j}=[0.1,0.1,0.1 ; 0.1,0.1$, $0.1 ; 0.1,0.1,0.1]$ (\$/year), General parameters: $\alpha_{i j}=[0.2,0.2,0.2 ; 0.2,0.2,0.2 ; 0.2,0.2,0.2], \beta_{i j}=[0.1$, $0.1,0.1 ; 0.1,0.1,0.1 ; 0.1,0.1,0.1]$. The rest of the parameteric values are same as in the Example 7.1. The optimum solution, $l_{j}=[0.0767,0.0767,0.0959], B\left(l_{j}\right)=[18.2000,16.1000,40.6000], m_{i j}=[1,1,1], n_{i j}=$ $[3,3,3]$, the optimal order quantity is given in the Table 6 the profit on three items for three consignee are $\left[P_{2}^{11}, P_{2}^{21}, P_{2}^{21}\right]=[3738.91,2467.3379,1764.9678],\left[P_{2}^{12}, P_{2}^{22}, P_{2}^{22}\right]=[2254.8835,2929.1406,2273.6092]$, $\left[P_{2}^{13}, P_{2}^{23}, P_{2}^{23}\right]=[1112.6775,1743.5042,1470.9505]$, the profit of three consignee is $[7971.2157,7457.6333$, 4327.1322] the overall profit of the supply chain is 19755.981 . 
TABle 5. Summarized lead time data.

\begin{tabular}{lll}
\hline \hline Consignee $j$ & Lead time (year) & $B\left(l_{j}\right)(\$ /$ shipment $)$ \\
\hline & $56 / 365=0.15342$ & 0 \\
1 & $42 / 365=0.11506$ & 1.4 \\
& $28 / 365=0.076712$ & 18.2 \\
& $21 / 365=0.05753$ & 53.20 \\
\hline & $49 / 365=0.13424$ & 0 \\
& $35 / 365=0.095890$ & 7 \\
& $28 / 365=0.076712$ & 16.1 \\
& $21 / 365=0.057534$ & 51.8 \\
\hline & $63 / 365=0.1726$ & 0 \\
& $49 / 365=0.13424$ & 5.6 \\
& $35 / 365=0.09589$ & 40.6 \\
& $28 / 365=0.076712$ & 75.6 \\
\hline
\end{tabular}

TABLE 6. Optimal values.

\begin{tabular}{|c|c|c|c|c|c|c|c|}
\hline \multirow{2}{*}{$\begin{array}{l}\text { Example/ } \\
\text { Case }\end{array}$} & \multirow{2}{*}{$\begin{array}{l}\text { Consignee } \\
j\end{array}$} & \multirow[b]{2}{*}{$l_{j}$} & \multirow[b]{2}{*}{$k_{i j}$} & \multirow{2}{*}{$\begin{array}{l}\text { Item } \\
m_{i j} \\
\end{array}$} & \multicolumn{2}{|c|}{$i=[1,2,3]$} & \multirow[b]{2}{*}{ Profit } \\
\hline & & & & & $n_{i j}$ & $q_{i j}$ & \\
\hline \multirow{3}{*}{1} & 1 & 0.0767 & & {$[1,1,1]$} & {$[3,3,3]$} & {$[128.84105,96.193021,68.123938]$} & \multirow{3}{*}{19096.861} \\
\hline & 2 & 0.0767 & - & {$[1,1,1]$} & {$[3,3,3]$} & {$[104.70503,102.54538,80.836474]$} & \\
\hline & 3 & 0.0959 & & {$[1,1,1]$} & {$[3,3,3]$} & {$[111.80159,106.69594,82.509551]$} & \\
\hline \multirow{3}{*}{2} & 1 & 0.0767 & & {$[1,1,1]$} & {$[3,3,3]$} & {$[134.41367,100.4769,70.809769]$} & \multirow{3}{*}{19755.981} \\
\hline & 2 & 0.0767 & - & {$[1,1,1]$} & {$[3,3,3]$} & {$[109.4138,106.88374,84.518569]$} & \\
\hline & 3 & 0.0959 & & {$[1,1,1]$} & {$[3,3,3]$} & {$[115.34919,109.70609,84.961654]$} & \\
\hline \multirow{3}{*}{3} & 1 & 0.1151 & {$[4,4,4]$} & {$[1,1,1]$} & {$[5,5,5]$} & {$[76.399709,57.672644,39.242718]$} & \multirow{3}{*}{17179.512} \\
\hline & 2 & 0.0959 & {$[4,4,4]$} & {$[1,1,1]$} & {$[5,5,5]$} & {$[61.565756,62.568235,47.485165]$} & \\
\hline & 3 & 0.1342 & {$[4,4,4]$} & {$[1,1,1]$} & {$[5,5,5]$} & {$[60.549037,61.549789,44.872583]$} & \\
\hline \multirow{3}{*}{4} & 1 & 0.1151 & {$[5,5,5]$} & {$[1,1,1]$} & {$[6,6,6]$} & {$[70.557926,53.168928,35.554063]$} & \multirow{3}{*}{17832.472} \\
\hline & 2 & 0.0959 & {$[5,5,5]$} & {$[1,1,1]$} & {$[6,6,6]$} & {$[56.473436,58.181526,43.846176]$} & \\
\hline & 3 & 0.1342 & {$[5,5,5]$} & {$[1,1,1]$} & {$[6,6,6]$} & {$[54.848228,56.1366,40.588412]$} & \\
\hline
\end{tabular}

Notes. The results of the four examples/cases are given in Table 6. Of those four results, we have bolded the value (i.e., "19755.981") to show that Example 7.2/Case 2 results are more profitable compared to the other three examples/cases results.

Example 7.3. For Case 3. $\left(h_{m i j}^{p}<h_{r i j}^{p}\right)$. This example takes the data from the Example 7.1 excluding the physical holding cost of consignor $h_{m i j}^{p}$ and consignee $h_{r i j}^{p}$. Instead we take $h_{m i j}^{p}=[7,6.8,7 ; 8,7,8 ; 8.5$, $7,7.8](\$ /$ unit/year $), h_{r i j}^{p}=[15,14.5,16 ; 14.8,16.7,15.9 ; 15,15.7,16](\$ /$ unit/year $), \varphi_{h_{r i j 4}^{p}}=[13,13$, $13 ; 13,13,13 ; 13,13,13], \varphi_{h_{r i j 3}^{p}}=[9,9,9 ; 9,9,9 ; 9,9,9], \varphi_{h_{r i j 2}^{p}}=[10,10,10 ; 10,10,10 ; 10,10,10]$, $\varphi_{h_{r i j 1}^{p}}^{p}=[14,14,14 ; 14,14,14 ; 14,14,14], \varphi_{h_{m i j 4}^{p}}=[5,5,5 ; 5,5,5 ; 5,5,5], \varphi_{h_{m i j 3}^{p}}=[2,2,2 ; 2,2,2 ;$ $2,2,2], \varphi_{h_{m i j 2}^{p}}=[3,3,3 ; 3,3,3 ; 3,3,3], \varphi_{h_{m i j 1}^{p}}=[6,6,6 ; 6,6,6 ; 6,6,6]$. The optimum values, $l_{j}=$ $[0.1151,0.0959,0.1342], B\left(l_{j}\right)=[1.4000,7.0000,5.6000], k_{i j}=[4,4,4], m_{i j}=[1,1,1], n_{i j}=[5,5,5]$, the profit on three items for three consignee are $\left[P_{3}^{11}, P_{3}^{21}, P_{3}^{21}\right]=[3299.3444,2145.4999,1539.6257],\left[P_{3}^{12}, P_{3}^{22}, P_{3}^{22}\right]=$ $[1902.2614,2615.3974,1949.3164],\left[P_{3}^{13}, P_{3}^{23}, P_{3}^{23}\right]=[834.41271,1615.2576,1278.3967]$, the total profit earned by the each conisgnee is $[6984.4699,6466.9752,3728.067]$, the overall profit of supply chain is 17179.512 .

Example 7.4. For Case 4. $\left(h_{m i j}^{p}<h_{r i j}^{p}\right)$. The parametric values of $I_{v i j}, \alpha_{i j}, \beta_{i j}$ are same as in the Example 7.2 and the values of $h_{m i j}^{p}, h_{r i j}^{p}$ are taken in account from Example 7.3. The remaining data are same as from the Example 7.1. The optimum values, $l_{j}=[0.1151,0.0959,0.1342], B\left(l_{j}\right)=$ 
$[1.4000,7.0000,5.6000], k_{i j}=[5,5,5], m_{i j}=[1,1,1], n_{i j}=[6,6,6]$, the profit on three items for three consignee are $\left[P_{4}^{11}, P_{4}^{21}, P_{4}^{21}\right]=[3410.6661,2239.1973,1581.7952],\left[P_{4}^{12}, P_{4}^{22}, P_{4}^{22}\right]=[1980.9267,2716.1003,1999.9991]$, $\left[P_{4}^{13}, P_{4}^{23}, P_{4}^{23}\right]=[901.17809,1689.6391,1312.9704]$, the total profit of three consignee is $[7231.6586,6697.0261$, 3903.7877], the overall profit of supply chain is 17832.472 .

The optimal solution for all four examples (four cases) are given in Table 6 and the profit obtained from the above four examples are compared in graphical representation 5.

\section{Discussion of the Results}

This section describes the discussion of the numerical results of the proposed model.

(1) The results of the four Examples 7.1-7.4 demonstrate that the supply chain achieves more profitability if the consignor has a higher physical holding cost $h_{m i j}^{p}$ than the consignee's physical holding cost $h_{r i j}^{p}$.

(2) If $h_{m i j}^{p}$ is less than $h_{r i j}^{p}$, the proposed model yields a lower profit, as is clear from the results of Cases 3 and 4 .

(3) The delay in shipment affects the profitability of the supply chain, which can be clearly seen in Figure 5.

(4) From the results of Example 7.2, it is evident that delaying the payment strategy can lead to higher profits.

\section{MANAGERIAL INSIGHTS}

This article analyzes the best strategy to maximize profits through late shipments and late payments. Moreover, it gives a comparison in four cases with respect to delay in payment and delay in shipment under a controllable lead time, and the managerial insights from those comparisons are as follows:

(1) The CS agreement policy favours both the consignor and the consignee, who can save funds by sharing the cost of holding the goods physically and financially.

(2) The manager will get more profit if case 2 (CS policy with DIP - NDIS under CLT) is established than the other three cases.

(3) In order to relate this model to reality, all basic inventory costs for $y$ items and $z$ consignees are considered to be imprecise, which can be very helpful for managers in dealing with ambiguous situations.

(4) Under the CS policy, the consignee is not required to pay until the products are sold. Whereas, if the consignee is unable to sell all those products, they can return the products to the consignor, therefore, the consignor has to face the risks and rewards of ownership.

\section{Conclusion And Future Directions}

This article has considered a single-consignor multi-consignee for multi-item under controllable lead time in a fuzzy environment. This paper adopts the CS policy, in particular, which is more beneficial for the consignor. This paper compares four different cases to show which cases are the most profitable for the supply chain. Moreover, this paper studies the impacts of controllable lead time for multiple consignees, which is a more critical and practical factor, and this never been studied under CS policies. The numerical results showed that the supply chain players (consignor and consignee) attain the highest profit in case 4 compared to case 3 , and case 1 attains higher profit than case 4 . However, case 2 was shown to be the most profitable when compared to all other cases. This model can be extended in many ways; basically, this model has some limitations, so it is possible to develop this model by resolving these limitations. Primarily in this model, we assume that the production process is perfect, so it can be extended by turning this model into an imperfect production process. Another extension is possible by relaxing the equal-sized shipment and fixed demand rate in the proposed model (refer, [11,38] and Ganesh Kumar and Uthayakumar [10] for unequal-sized shipments, Sarkar et al. [29] for price and advertisement-dependent demand, Karthick and Uthayakumar [19,20] for fuzzy demand). Exploring the changes that occur in this model by combining concepts such as learning and forgetting can be considered an extension (refer, [13]). The production rate is assumed to be constant in this model, so considering the production 


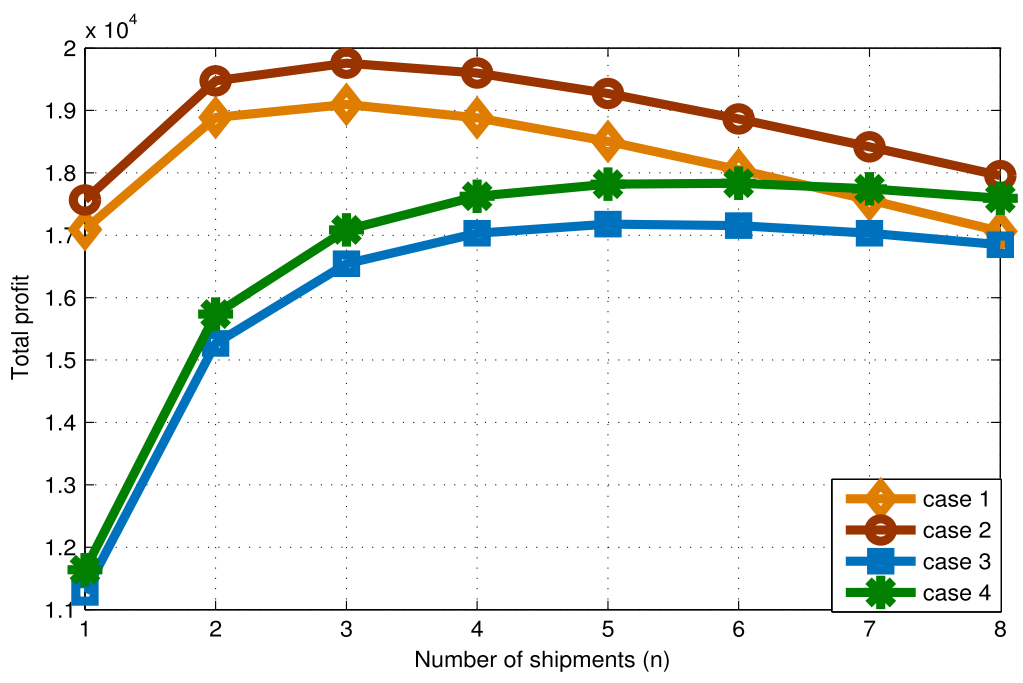

Figure 5. Total profit $d_{0}\left(\tilde{P}_{c}, \tilde{0}\right)$ with respect to number of shipments $\left(n_{i j}\right)$.

rate as a variable for a flexible production process is another extension (refer, [17,27]). The incorporation of the consignee's royalty reduction (refer, [28]) and radio frequency identification (refer, [31]) in the CS policy would be a reasonable extension of this model.

Acknowledgements. The work of the authors are supported by UGC - SAP, Department of Mathematics, The Gandhigram Rural Institute (Deemed to be University) Gandhigram, Dindigul District, Tamil Nadu, India. Pincode: 624302 .

Conflict of interest. The authors declare that they have no conflict of interest.

\section{REFERENCES}

[1] S.P. Aggarwal and C.K. Jaggi, Ordering policies of deteriorating items under permissible delay in payments. J. Oper. Res. Soc. 46 (1995) 658-662.

[2] B. Ahmad and L. Benkherouf, On an optimal replenishment policy for inventory models for non-instantaneous deteriorating items with stock dependent demand and partial backlogging. RAIRO:OR 54 (2020) 69-79.

[3] S.M. Ali and K. Nakade, Scenario-based supply chain disruptions management framework: a quantitative approach. Innov. Supply Chain Manage. 8 (2014) 81-91.

[4] K.M. Björk, An analytical solution to a fuzzy economic order quantity problem. Int. J. Approximate Reasoning 50 (2009) $485-493$.

[5] M. Braglia and L. Zavanella, Modelling an industrial strategy for inventory management in supply chains: the "Consignment Stock" case. Int. J. Prod. Res. 41 (2003) 3793-3808.

[6] S. Bylka, The consignment stock of inventories under buyer's warehouse space limitation. Int. J. Prod. Res. 58 (2020) $912-930$.

[7] A. Chakraborty, T. Maiti and B.C. Giri, Consignment stock policy in a closed-loop supply chain. RAIRO:OR 55 (2021) S1913-S1934.

[8] N. Çömez-Dolgan, L. Moussawi-Haidar and M.Y. Jaber, A buyer-vendor system with untimely delivery costs: traditional coordination vs. VMI with consignment stock. Comput. Ind. Eng. 154 (2021) 107009.

[9] S. Ebrahimi, S.M. Hosseini-Motlagh and M. Nematollahi, Proposing a delay in payment contract for coordinating a two-echelon periodic review supply chain with stochastic promotional effort dependent demand. Int. J. Mach. Learn. Cybern. 10 (2019) $1037-1050$.

[10] M. Ganesh Kumar and R. Uthayakumar, Modelling on vendor-managed inventory policies with equal and unequal shipments under GHG emission-trading scheme. Int. J. Prod. Res. 57 (2019) 3362-3381.

[11] B. Ganguly, B. Sarkar, M. Sarkar, S. Pareek and M. Omair, Influence of controllable lead time, premium price, and unequal shipments under environmental effects in a supply chain management. RAIRO:OR 53 (2019) 1427-1451. 
[12] A. Gharaei, M. Karimi and S.A.H. Shekarabi, An integrated multi-product, multi-buyer supply chain under penalty, green, and quality control polices and a vendor managed inventory with consignment stock agreement: the outer approximation with equality relaxation and augmented penalty algorithm. Appl. Math. Modell. 69 (2019) 223-254.

[13] B.C. Giri and M. Masanta, A closed-loop supply chain model with uncertain return and learning-forgetting effect in production under consignment stock policy. Oper. Res. 20 (2020) 1-29. DOI: 10.1007/s12351-020-00571-9.

[14] B.C. Giri, A. Chakraborty and T. Maiti, Effectiveness of consignment stock policy in a three-level supply chain. Oper. Res. 17 (2017) 39-66.

[15] R.M. Hill, The optimal production and shipment policy for the single-vendor single-buyer integrated production-inventory problem. Int. J. Prod. Res. 37 (1999) 2463-2475.

[16] Q. Huang and J. Chen, A note on "Modelling an industrial strategy for inventory management in supply chains: the 'Consignment Stock'case". Int. J. Prod. Res. 47 (2009) 6469-6475.

[17] R. Jamshidi, S.F. Ghomi and B. Karimi, Flexible supply chain optimization with controllable lead time and shipping option. Appl. Soft Comput. 30 (2015) 26-35.

[18] J.K. Jha and K. Shanker, Single-vendor multi-buyer integrated production-inventory model with controllable lead time and service level constraints. Appl. Math. Model. 37 (2013) 1753-1767.

[19] B. Karthick and R. Uthayakumar, Optimizing an imperfect production model with varying setup cost, price discount, and lead time under fuzzy demand. Process Integr. Optim. Sustain. 5 (2021) 13-29.

[20] B. Karthick and R. Uthayakumar, A multi-item sustainable manufacturing model with discrete setup cost and carbon emission reduction under deterministic and trapezoidal fuzzy demand. Process Integr. Optim. Sustain. 5 (2021) 1-39. DOI: 10.1007/s41660-021-00159-6.

[21] N. Kazemi, E. Ehsani and M.Y. Jaber, An inventory model with backorders with fuzzy parameters and decision variables. Int. J. Approximate Reasoning 51 (2010) 964-972.

[22] L.Y. Ouyang and J.S. Yao, A minimax distribution free procedure for mixed inventory model involving variable lead time with fuzzy demand. Comput. Oper. Res. 29 (2002) 471-487.

[23] S. Rani, R. Ali and A. Agarwal, Fuzzy inventory model for deteriorating items in a green supply chain with carbon concerned demand. Opsearch 56 (2019) 91-122.

[24] B. Sarkar, An EOQ model with delay in payments and stock dependent demand in the presence of imperfect production. Appl. Math. Comput. 218 (2012) 8295-8308.

[25] S.K. Sardar and B. Sarkar, How does advanced technology solve unreliability under supply chain management using game policy? Mathematics 8 (2020) 1191.

[26] B. Sarkar, B. Mandal and S. Sarkar, Quality improvement and backorder price discount under controllable lead time in an inventory model. J. Manuf. Syst. 35 (2015) 26-36.

[27] B. Sarkar, A. Majumder, M. Sarkar, N. Kim and M. Ullah, Effects of variable production rate on quality of products in a single-vendor multi-buyer supply chain management. Int. J. Adv. Manuf. Technol. 99 (2018) 567-581.

[28] B. Sarkar, C. Zhang, A. Majumder, M. Sarkar and Y.W. Seo, A distribution free newsvendor model with consignment policy and retailer's royalty reduction. Int. J. Prod. Res. 56 (2018) 5025-5044.

[29] B. Sarkar, M. Omair and N. Kim, A cooperative advertising collaboration policy in supply chain management under uncertain conditions. Appl. Soft Comput. 88 (2020) 105948.

[30] B. Sarkar, B.K. Dey, M. Sarkar, S. Hur, B. Mandal and V. Dhaka, Optimal replenishment decision for retailers with variable demand for deteriorating products under a trade-credit policy. RAIRO:OR $\mathbf{5 4}$ (2020) 1685-1701.

[31] S.K. Sardar, B. Sarkar and B. Kim, Integrating machine learning, radio frequency identification, and consignment policy for reducing unreliability in smart supply chain management. Processes 9 (2021) 247.

[32] S. Shabani, A. Mirzazadeh and E. Sharifi, A two-warehouse inventory model with fuzzy deterioration rate and fuzzy demand rate under conditionally permissible delay in payment. J. Ind. Prod. Eng. 33 (2016) 134-142.

[33] A.K. Sharma, S. Tiwari, V.S.S. Yadavalli and C.K. Jaggi, Optimal trade credit and replenishment policies for non-instantaneous deteriorating items. RAIRO:OR 54 (2020) 1793-1826.

[34] D. Shin, R. Guchhait, B. Sarkar and M. Mittal, Controllable lead time, service level constraint, and transportation discounts in a continuous review inventory model. RAIRO:OR 50 (2016) 921-934.

[35] C. Srinivas and C.S.P. Rao, Optimization of supply chains for single-vendor-multibuyer consignment stock policy with genetic algorithm. Int. J. Adv. Manuf. Technol. 48 (2010) 407-420.

[36] G. Valentini and L. Zavanella, The consignment stock of inventories: industrial case and performance analysis. Int. J. Prod. Econ. 81 (2003) 215-224.

[37] H. Yi and B.R. Sarker, An optimal consignment stock production and replenishment policy with controllable lead time. Int. J. Prod. Res. 51 (2013) 6316-6335.

[38] H.F. Yu and W.K. Hsu, An integrated inventory model with immediate return for defective items under unequal-sized shipments. J. Ind. Prod. Eng. 34 (2017) 70-77.

[39] S.K. Zahran, M.Y. Jaber and S. Zanoni, The consignment stock case for a vendor and a buyer with delay-in-payments. Comput. Ind. Eng. 98 (2016) 333-349.

[40] L. Zavanella and S. Zanoni, A one-vendor multi-buyer integrated production-inventory model: the "Consignment Stock" case. Int. J. Prod. Econ. 118 (2009) 225-232. 


\section{Subscribe to Open (S2O) \\ A fair and sustainable open access model}

This journal is currently published in open access with no charge for authors under a Subscribe-to-Open model (S2O). Open access is the free, immediate, online availability of research articles combined with the rights to use these articles fully in the digital environment.

$\mathrm{S} 2 \mathrm{O}$ is one of the transformative models that aim to move subscription journals to open access. Every year, as long as the minimum amount of subscriptions necessary to sustain the publication of the journal is attained, the content for the year is published in open access.

\section{Ask your library to support open access by subscribing to this $\mathrm{S} 2 \mathrm{O}$ journal.}

Please help to maintain this journal in open access! Encourage your library to subscribe or verify its subscription by contacting subscribers@edpsciences.org

We are thankful to our subscribers and sponsors for making it possible to publish the journal in open access, free of charge for authors. More information and list of sponsors: https://www.edpsciences.org/en/maths-s2o-programme 